\title{
Radiative budget in the presence of multi-layered aerosol structures in the framework of AMMA SOP-0
}

\author{
J.-C. Raut and P. Chazette \\ Laboratoire des Sciences du Climat et de l'Environnement, Laboratoire mixte CEA-CNRS-UVSQ, CEA Saclay, 91191 \\ Gif-sur-Yvette, France
}

Received: 6 May 2008 - Published in Atmos. Chem. Phys. Discuss.: 1 July 2008

Revised: 13 October 2008 - Accepted: 13 October 2008 - Published: 28 November 2008

\begin{abstract}
This paper presents radiative transfer calculations performed over Niamey in the UV-Visible range over the period 26th January-1st February 2006 during the African Multidisciplinary Monsoon Analysis (AMMA) international program. Climatic effects of aerosols along the vertical column have required an accurate determination of their optical properties, which are presented here for a variety of instrumented platforms: Ultralight aircraft, Facility for Airborne Atmospheric Measurements (FAAM) research aircraft, AERONET station. Measurements highlighted the presence of a multi-layered structure of mineral dust located below and biomass-burning particles in the more elevated layers. Radiative forcing was affected by both the scattering and absorption effects governed by the aerosol complex refractive index (ACRI). The best agreement between our results and AERONET optical thicknesses, ground-based extinction measurements and $\mathrm{NO}_{2}$ photolysis rate coefficient was found using the synergy between all the instrumented platforms. The corresponding averaged ACRI at $355 \mathrm{~nm}$ were $1.53( \pm 0.04)-0.047 \mathrm{i}( \pm 0.006)$ and $1.52( \pm 0.04)-0.008 \mathrm{i}$ $( \pm 0.001)$ for biomass-burning and mineral dust aerosols, respectively. Biomass-burning aerosols were characterized by single-scattering albedo ranging from 0.78 to 0.82 and asymmetry parameter ranging from 0.71 to 0.73 . For dust aerosols, single-scattering albedo (asymmetry parameter) ranged from 0.9 to 0.92 (0.73 to 0.75 ). The solar energy depletion at the surface is shown to be $\sim-21.2( \pm 1.7) \mathrm{W} / \mathrm{m}^{2}$ as a daily average. At the TOA, the radiative forcing appeared slightly negative but very close to zero $\left(\sim-1.4 \mathrm{~W} / \mathrm{m}^{2}\right)$. The corresponding atmospheric radiative forcing was found to be
\end{abstract}

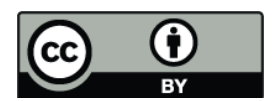

Correspondence to: J.-C. Raut (jean-christophe.raut@1sce.ipsl.fr) $\sim 19.8( \pm 2.3) \mathrm{W} / \mathrm{m}^{2}$. Mineral dust located below a more absorbing layer act as an increase in surface reflectivity of $\sim 3-$ $4 \%$. The radiative forcing is also shown to be highly sensitive to the optical features of the different aerosol layers (ACRI, optical thickness and aerosol vertical distribution).

\section{Introduction}

In contrast to the radiative forcing attributed to greenhouse gases, which may be estimated to a reasonably high degree of accuracy, the uncertainties related to aerosol radiative forcings remain very large. Hence, aerosol particles have received an increasing amount of attention in the recent years. Scattering and absorption by aerosols have a significant impact on the energy budget of the atmosphere (Alpert et al., 1998), as well as on the surface (Fouquart et al., 1987). They reduce the solar radiative flux at the surface (Charlson et al., 1992), can limit surface evaporation and surface heat fluxes, and may modify large-scale atmospheric circulations as shown during the Indian Ocean experiment (INDOEX, Ramanathan et al., 2001; Léon et al., 2005). They also influence the climate altering the radiative properties and lifetime of clouds when particles act as Cloud Condensation Nuclei (Twomey et al., 1984). Atmospheric dynamics and convection can therefore be affected by aerosol (Ackerman et al., 2000). Assessing their influence is made complex by the high spatial and temporal variability of aerosol physical, chemical, and optical properties. This problem arises mainly due to diverse range of aerosol sources and their short residence times in the atmosphere.

Among all sources of atmospheric particles, Western Africa is the world's largest source of biomass burning aerosols (Andreae and Merlet, 2001) and mineral dust

Published by Copernicus Publications on behalf of the European Geosciences Union. 
(Prospero et al., 2002). The regional impacts of mineral dust events have been studied, especially over sea areas, in previous multi-disciplinary campaigns involving groundbased monitoring, research aircraft, satellite observations, e.g. Mediterranean Dust experiment (MEDUSE, Hamonou et al., 1999; Dulac and Chazette, 2003), Saharan Dust Experiment (SHADE, Haywood et al., 2003b) and the Aerosol Characterisation Experiment (ACE-Asia, Seinfeld et al., 2004). However, there are limited studies of mineral dust in mixtures with biomass burning aerosol. The Sahelian region is a major global source of biomass-burning aerosol during the dry season (Bond et al., 2004) with maximum emissions occurring from December to March (Swap et al., 2003). Their black carbon content depending on fire intensity and vegetation density clearly affects the radiation balance. Such submicronic aerosol particles have a strong effect on solar radiation but have negligible effect on terrestrial radiation because aerosol optical depth decreases strongly with increasing wavelength leading to the tendency for submicron aerosol layers to be transparent at infrared wavelengths (Harshvardhan, 1993).

Previous observations of biomass-burning aerosols have been performed mainly in South America (e.g. Reid et al. 1998; Kaufman et al., 1998; Andrea et al., 2004), in Southern Africa (i.e. Swap et al., 2002; Myhre et al., 2003) and in Western India (e.g. Ramanathan et al., 2001; Pelon et al., 2002). Nevertheless, few observations are available about the radiative impact of burning of agricultural waste in the Sahelian region that likely influence the African monsoon cycle, living conditions and human health in that region.

Moreover, in the Sahel dust and biomass burning aerosols co-exist and may interact on a microphysical level, a process that has not been investigated yet in past field experiments. The objective of the Dust and Biomass Burning Experiment (DABEX), as part of African Monsoon Multidisciplinary Analysis (AMMA) (Redelsperger et al., 2006), was to characterize the optical properties and direct radiative forcing of dust and biomass-burning aerosols in the Sahel. DABEX was conducted during the AMMA dry season Special Observation Period SOP-0 in January-February 2006 over Western Africa. Haywood et al. (2008) provides an overview of the experimental objectives, platforms, and meteorology during DABEX and AMMA SOP-0. This study complements the works of Johnson et al. (2008a), Osborne et al. (2008) and Mallet et al. (2008) which report the optical characterization of biomass-burning aerosols, mineral dust particles and radiative effects of biomass-burning particles in Northern Benin, respectively.

This paper presents radiative transfer calculations performed over Niamey in the UV-Visible range over the period 26th January-1st February. Accurate calculations of the radiative effects of dust and biomass-burning aerosols through the atmospheric column require high quality measurements of their microphysical and optical properties. These properties are derived in this study from a variety of instrumented platforms, including ground-based, airborne and integratedcolumn remote sensing. The sensitivity of the radiative effects to optical features of the different layers will be also presented.

\section{Tools}

\subsection{Instrumental set-up}

Ground-based observations at Niamey $\left(13^{\circ} 30^{\prime} \mathrm{N}, 2^{\circ} 10^{\prime} \mathrm{E}\right.$, Niger) have been complemented by ultra-light aircraft (ULA) and Facility for Airborne Atmospheric Measurements (FAAM) aircraft measurements, which provide a characterization of dust and biomass burning aerosols microphysical and optical properties within the low and middle troposphere (between the ground to $5 \mathrm{~km}$ above the mean sea level (amsl)).

\subsubsection{ULA platform}

The ULA used was built by the Air Création Company (www.aircreation.fr). It is a high performance model Tanarg 912-XS weight-shift control ULA platform. Technical features are fully described in Chazette et al. (2007). The advantages of such an aircraft are its manoeuvrability in small atmospheric volumes, its ability to cruise at levels from nearsurface up to more than $5.5 \mathrm{~km}$, and its low speed of flight, which minimizes the isokinetic problems involved in in situ aerosol measurements. Furthermore, it can use small airfields for takeoff and landing. The ULA performed 17 flights within the vicinity of Niamey: ULA-1 to 17 . The aerosol payload was composed of an eye-safe backscatter lidar emitting in the ultraviolet and a scatterometer to measure the aerosol side-scattering in the near-infrared described in the following.

The Lidar Aérosol UltraViolet Aéroporté (LAUVA) is a homemade prototype instrument developed by the Commissariat à l'Energie Atomique (CEA) and the Centre National de la Recherche Scientifique (CNRS). It was designed to monitor the aerosol dispersion in the low and middle troposphere. It operates with a Nd:Yag laser at the wavelength of $355 \mathrm{~nm}$. It is light, compact, eye-safe and suitable for an airborne platform. Its resolution along the line of sight is $1.5 \mathrm{~m}$. During flights, the combination of horizontal shooting during ascent and descent phases with nadir shooting during transects enabled us to derive vertical profiles of backscatterto-extinction ratio (BER) and backscattering coefficient. Further description of this data retrieval procedure can be found in Chazette et al. (2007).

The Personal DataRam (PdRam) is a small portable nephelometer-type instrument documented in Dulac et al. (2001), who operated it under a sounding balloon off the coast of the Sahara. It measures aerosol side-scattering in the angular range of $45-95^{\circ}$ at the wavelength of $880 \mathrm{~nm}$ (bandwidth of $40 \mathrm{~nm}$ ). The instrument is calibrated in terms of Mie 
scattering using a gaseous reference scatterer and in terms of aerosol extinction at $870 \mathrm{~nm}$ against a ground-based sunphotometer (Chazette et al., 2007).

A Vaisala meteorological probe type PTU200 was used to measure the temperature, the relative humidity, and the atmospheric pressure.

In addition, a global positioning system manufactured by Trimble was used to measure the location of the ULA (with accuracies of 15 and $10 \mathrm{~m}$ for vertical and horizontal positions, respectively), and an artificial horizon (electronic flight information system) manufactured by Dynon Avionics was used to locate the lidar line of sight in the three dimensions of space, with an accuracy close to $0.5^{\circ}$.

\subsubsection{FAAM platform}

The Facility for Airborne Atmospheric Measurements (FAAM) BAe-146 meteorological research aircraft is used by the UK atmospheric research community. It was based at Niamey, Niger from 11th January to 3rd February. All flights started and ended at Niamey International Airport. The aircraft performed 13 flights within the vicinity of $\mathrm{Ni}$ amey. It contains a comprehensive suite of instruments measuring aerosol, cloud, chemical tracers, solar and terrestrial radiative fluxes and standard meteorological variables that are described in Johnson et al. (2008a) and summarized below.

Aerosol size distributions were measured by the Passive Cavity Aerosol Spectrometer Probe 100X (PCASP), mounted externally under the aircraft wing and sizing aerosols with radii in the range $0.05-1.5 \mu \mathrm{m}$. The PCASP is calibrated using latex spheres of known sizes. The refractive index of latex (1.58) differs slightly from those of biomassburning or mineral dust aerosols. This causes the PCASP to underestimate aerosol radius by a factor of 0.93 over the optically active part of the size-spectrum $(0.1-0.3 \mu \mathrm{m})$ (Haywood et al., 2003a). For larger (super-micronic) particles, aircraft sampling is always problematic.

A three-wavelength $(450,550$ and $700 \mathrm{~nm})$ nephelometer (manufactured by TSI ${ }^{\circledR}$ was used onboard the aircraft. This instrument uses a Rosemount head for its inlet and measures the aerosol scattering coefficient in a $7-170^{\circ}$ range of scattering angle (Bodhaine et al., 1991). To compensate for the limited range of scattering angles, the nephelometer data was calibrated using Anderson and Ogren (1998) sub-micron corrections. Also, because sampling efficiency drops off rapidly with particle size above about $1 \mu \mathrm{m}$ radius (Haywood et al., 2003a) a correction was made to account for large particle losses (Osborne et al. 2008). To allow comparison with the lidar that operates at $355 \mathrm{~nm}$, the scattering coefficient of the nephelometer has been extrapolated in wavelength using the Angström exponent derived from the $450 \mathrm{~nm}$ and $550 \mathrm{~nm}$ channels. The nephelometer heats air in the instrument, which may lead to partial or complete evaporation of any water present around the aerosols. However, since the ambient relative humidity was very low (mean of $40 \%$ and standard deviation of $30 \%$ ) during most flights it is unlikely that the aerosols contained much water.

A Particle Soot Absorption Photometer (PSAP), also equipped with a Rosemount inlet, measures the aerosol absorption coefficient at $567 \mathrm{~nm}$, inferred from loss of transmission of light through a filter. The PSAP absorption coefficient was corrected for errors in filter exposure area, air flow rate, over-reading of absorption, the influence of scattering by aerosols collected on the filter, and multiple scattering within the filter following the methods of Bond et al. (1999). An adjustment was also made to convert the absorption coefficient measured at $567 \mathrm{~nm}$ to $355 \mathrm{~nm}$, the wavelength of the LAUVA. For this correction the absorption is assumed to vary as the reciprocal of wavelength, as in Reid and Hobbs (1998). Aircraft altitudes were measured by a global positioning system.

\subsubsection{Ground measurements}

AErosol RObotic NETwork (AERONET) aerosol optical depths (AOD, level 2.0) and aerosol size distributions of the Banizoumbou $\left(13^{\circ} 31^{\prime} \mathrm{N}, 2^{\circ} 34^{\prime} \mathrm{E}\right)$ ground site located at about $50 \mathrm{~km}$ East from Niamey are used in this paper (Rajot et al., 2008). The retrievals were carried out using Version 2 of the inversion algorithm (Dubovik et al., 2006). The channels of the sunphotometer used for this study are centered at $438 \mathrm{~nm}$ and $669 \mathrm{~nm}$, with bandwidths of less than $20 \mathrm{~nm}$ and the instrument field of view is about $1^{\circ}$ (Holben et al., 1998). The AERONET database gives a maximal absolute uncertainty of 0.02 for the optical thickness due to calibration uncertainty for the field instruments. Extrapolation is then used to estimate the AOD at $355 \mathrm{~nm}$ for comparison with the lidar. Values have been averaged at the closest time of the flights. In particular, no measurement was available on the 26th January before 13:30 UTC and thin cloud on 28th January prevented accurate retrievals by AERONET so no AOD data was available.

The actinic flux is the radiation quantity that best describes the geometry in photoreactions. It is sensitive to aerosol presence and is a function of the aerosol optical parameters. To monitor the actinic flux at the ground station, a $\mathrm{JNO}_{2}$ optical actinometer (manufactured by Metcon, Glashütten, Germany) has been installed. It is dedicated to the measurement of the photodissociation rate coefficient $\mathrm{J}\left(\mathrm{NO}_{2}\right)$ of $\mathrm{NO}_{2}$ molecule, which is the probability for a $\mathrm{NO}_{2}$ single molecule to be photodissociated by absorbing solar radiation. $\mathrm{J}\left(\mathrm{NO}_{2}\right)$ is a function of the actinic flux, the photodissociation quantum yield and the absorption cross section of the $\mathrm{NO}_{2}$ molecule. Actinic flux is measured by a radiometer made up of two identical detectors with uniform response over $2 \pi$ sr. Using the calibration coefficient determined from a comparison with a chemical actinometer, the measured actinic flux is directly converted into $\mathrm{J}\left(\mathrm{NO}_{2}\right)$ values $\left(\right.$ in s$\left.^{-1}\right)$ with a relative accuracy of about $1 \%$. Both detectors were set up at about 6 
meters above the ground, one pointing up and the second one parallel but pointing down. Such a configuration allows the determination of the upward $\mathbf{J}\left(\mathrm{NO}_{2}\right)^{u}$ and downward contribution $\mathrm{J}\left(\mathrm{NO}_{2}\right)^{d}$ (Randriamiarisoa et al., 2004). This instrument was operated at Niamey airport. $\mathrm{J}\left(\mathrm{NO}_{2}\right)$ data are recordered every minute.

The Atmospheric Radiation Measurements (ARM; see http://www.arm.gov/sites/amf.stm) Mobile Facility (AMF) was installed at Niamey airport for the duration of the DABEX field campaign. Thus, scattering and absorption coefficients were also measured at the surface from a nephelometer working at 450, 550 and $700 \mathrm{~nm}$ and a PSAP operating at 467, 530 and $660 \mathrm{~nm}$ (Miller et al., 2007).

\subsubsection{Satellite observations}

The MODerate-resolution Imaging Spectroradiometer (MODIS) satellite observations (http://modis.gsfc.nasa.gov/) provide the Bidirectional Reflectance Distribution Function (BRDF) of each pixel in MODIS spectral "Land" bands, as well as for three broad bands $(0.3-0.7,0.7-5.0$, and $0.3-5.0 \mu \mathrm{m})$. They give data describing both directional hemispherical reflectance (black-sky albedo) and bihemispherical reflectance (white-sky albedo). These are intrinsic surface properties, independent of atmospheric state. They describe the upward scattering of the solar beam and of uniform diffuse irradiance, respectively. In this study, we used both Terra and Aqua data providing 16-day composites projected to a 0.05 degree $(5600 \mathrm{~m})$ latitude/longitude Climate Modeling Grid.

\subsection{Radiative transfer model}

\subsubsection{TUV model}

The estimation of the aerosol radiative forcing has been performed using the Tropospheric Ultraviolet and Visible (TUV) radiative transfer model. TUV was developed by Madronich and his colleagues at the US National Center for Atmospheric Research (http://cprm.acd.ucar.edu/Models/ TUV/, Madronich and Flocke, 1998) and uses the DIScrete ORdinates Radiative Transfer (DISORT) solver (Stamnes et al., 1988) modified for pseudo spherical geometry. Version 4.4, four-stream and sixteen-stream discrete ordinate calculations were used in this study to calculate the heating rate from 0 to $12 \mathrm{~km}$ and the aerosol radiative forcings at the surface and at the top of the atmosphere in the spectral interval 200-750 nm.

The TUV model has been chosen because it allows an accurate computation of actinic fluxes leading to a possible comparison of actinometer measurement with the retrieved photodissociation rate coefficient $\mathrm{J}\left(\mathrm{NO}_{2}\right)$ for each dataset. Models using the Atmospheric Laboratory for Applications and Science 3 (ATLAS-3) extraterrestrial solar spectrum, such as TUV model, are in better agreement with mea- surements, suggesting the appropriateness of ATLAS-3 for model calculations (Bais et al., 2003). Investigating the spectrally resolved actinic fluxes calculated by 16 models, Bais et al. (2003) showed that when all model input parameters except the extraterrestrial solar spectrum are the same, the calculated actinic flux spectrum based on ATLAS-3 compares better with the measurements at the ground in the region $300-400 \mathrm{~nm}$ than those based on Modtran 3 and Neckel and Labs (1984).

Another reason for choosing the TUV model is that we try to properly evaluate the aerosol complex refractive index (ACRI) in this paper for dust and biomass-burning aerosols at $355 \mathrm{~nm}$. An accurate assessment of the visible radiative impact of atmospheric aerosols can be carried out assuming that ACRI is constant between 0.3 and $0.8 \mu \mathrm{m}$ (Volz, 1973). In the near infrared spectrum, this hypothesis is not realistic any longer. Volz (1973) showed for instance that the real part of mineral dust particles sharply drops from 1.5 to 1.2 between 1 and $2 \mu \mathrm{m}$. Important spectral dependence of imaginary parts in shortwave infrared region was also observed for hygroscopic aerosols, such as biomass-burning particles. Our study thus focuses on radiative transfer calculations in UV-Visible domain and a discussion on the representativity of the results will be performed.

\subsubsection{Radiative approach}

Radiative transfer computations depend on several input parameters: spectral surface albedo, vertical profiles of atmospheric pressure, temperature, ozone, spectral aerosol extinction coefficient, single-scattering albedo $\left(\omega_{o}\right)$ and asymmetry factor $(g)$. Those aerosol dependent parameters can be determined from the aerosol complex refractive index (ACRI), aerosol size distribution and lidar or nephelometer measurements of aerosol extinction.

The TUV model has been slightly modified to take into account the vertical distribution of all optical parameters: extinction coefficient, single-scattering albedo, and asymmetry factor. To accurately describe the impact of the multilayered structure in the atmosphere, the model vertical grid has been divided into homogeneous layers of $0.1 \mathrm{~km}$ thickness from 0 to $5 \mathrm{~km}$ altitude, $0.5 \mathrm{~km}$ thickness from 5 to $12 \mathrm{~km}$, and $2 \mathrm{~km}$ thickness above $12 \mathrm{~km}$. Pressure, temperature and relative humidity vertical profiles used in the TUV were taken from measurements made onboard the FAAM aircraft and ULA during each flight. Ozone concentration profiles were also taken from measurements by the FAAM. Above $5 \mathrm{~km}$, the profiles of atmospheric constituents have been completed using the US Standard Atmosphere annual means of 1976 at $45^{\circ} \mathrm{N}$, which do not much differ from the tropical mean profiles above $5 \mathrm{~km}$ (McClatchey et al., 1972).

Two radiative transfer methods proposed by the radiative transfer modelling have been used: the 4-stream discrete ordinates method to simulate the irradiances (Stamnes et al., 1988) and a more precise approach to calculate the photolysis 
Table 1. Dates and times of flight profiles from the FAAM and ULA aircraft for the five selected case studies, plus AODs calculated at $355 \mathrm{~nm}$ from the aircraft profile and the AERONET sunphotometer at Banizoumbou.

\begin{tabular}{lcccccc}
\hline Case & Day & FAAM flight period (UTC) & FAAM AOD & ULA flight period (UTC) & ULA AOD & AERONET AOD \\
\hline 1 & 26 Jan & $08: 10-08: 34$ & 0.82 & $07: 09-09: 03$ & 0.54 & 0.65 \\
2 & 26 Jan & $10: 24-10: 37$ & 0.75 & $09: 59-10: 53$ & 0.66 & 0.65 \\
3 & 26 Jan & $11: 44-11: 58$ & 0.73 & $11: 30-12: 04$ & 0.56 & 0.65 \\
4 & 28 Jan & $09: 54-10: 11$ & 0.54 & $09: 12-11: 06$ & 0.46 & - \\
5 & 1 Feb & $11: 05-11: 21$ & 0.60 & $07: 31-09: 11$ & 0.43 & 0.46 \\
\hline
\end{tabular}

rates, the 16-stream discrete ordinates method, based on preferred directions along which the resolution of transfer radiative equation is done, allowing an accurate treatment of multiple scattering effects by aerosols.

Calculations of both direct $F_{\text {dir }}^{d}$ and diffuse downwelling $F_{\text {diff }}^{d}$ fluxes, and diffuse upwelling fluxes $F_{\text {diff }}^{u}$ in clear-sky conditions enabled the determination of the net radiative fluxes over the UV and visible spectrum for 24 hours periods with $1 \mathrm{~h}$ time resolution. Aerosol radiative forcings at the bottom of atmosphere (BOA, $\Delta F_{\mathrm{BOA}}$ ), at the top of the atmosphere (TOA, $\left.12 \mathrm{~km}, \Delta F_{\mathrm{TOA}}\right)$ and in the atmospheric layer containing the particles (ATM, $\Delta F_{\mathrm{ATM}}$ ) are then calculated. Heating rates due to the only presence of aerosols have then been calculated.

\section{Coherence of the experimental datasets}

Five case studies are considered in this study. They correspond to the five coordinated flights between ULA and FAAM aircraft. The three first cases correspond to B1632 (ULA-6), B163-4 (ULA-7a), B163-9 (ULA-7b) flights of 26 January, and the last ones to B164-2 (ULA-9) and B166-1 (ULA-17) flights of 28 January and 1 February, respectively. The profiles were all acquired quite close to Niamey (less than $100 \mathrm{~km}$ distance) and the corresponding flight periods are summarized in Table 1.

3.1 Vertical profiles of extinction coefficient, Angström exponent and water vapour

ULA, FAAM aircraft, ARM and AERONET datasets have been compared in the atmospheric column in terms of aerosol extinction coefficient, calculated as the sum of scattering and absorption for FAAM and ARM results, and plotted on Figs. 1 to 5 for each case.

All flights show similar vertical structures in the aerosol profile where aerosol extinction is highest in the lowest $1.5 \mathrm{~km}$ (cases 1 to 3 ) or $1 \mathrm{~km}$ (cases 4 and 5) of the atmosphere, illustrating the dominance of dust aerosols in the lowest layers. Above the dust, elevated layers of biomassburning aerosols are present at altitudes up to 4 or $5 \mathrm{~km}$. Above the biomass-burning layer aerosol extinction falls to negligible values. The mineral dust layers are distinguished from the biomass-burning aerosol layers by the very low (even negative) Angström exponent (between 355 and $880 \mathrm{~nm}$ ) in the first $2 \mathrm{~km}$. The dust layer is also accompanied by very high values of FAAM single-scattering albedo (0.96 to 0.98) (as consistent with Osborne et al., $2008)$ and a low values of water vapour mixing ratio $(0.002$ to 0.004$)$. In contrast, several layers between 1 and $5 \mathrm{~km}$ show a higher Angström exponent (0.5-1.5), a lower singlescattering albedo (0.85-0.9 from FAAM) and a higher water vapour mixing ratio $(0.004-0.007)$. These characteristics can be related to tropical air masses where biomass burning aerosols are present. The lower, stable and thermodynamically well-mixed layer seems to prevent dust and biomass burning aerosols from mixing together. However, mixing of dust and biomass burning aerosol did occur further south from where the fires occurred, which led to an appreciable amount of dust becoming lofted up into the "biomassburning" aerosol layer (Johnson et al., 2008a). An analysis of back-trajectories (not shown in this study) has indicated that the high concentrations of mineral dust aerosols were predominantly due to emissions from the Sahara desert and arid parts of the Sahel on the North or East of Niamey (Chazette et al., 2007). Because of the vicinity of Niamey city, it is also likely that biomass-burning aerosols from local fires and urban and industrial aerosols mixed with the dust in the boundary layer. Biomass-burning particles stem from elevated layers that have been transported thousands of kilometers across the continent. They originate from intense agricultural burning of crop debris or grass during the dry season (e.g. Haywood et al., 2008).

The ULA and FAAM profiles (Figs. 1-5) reproduce the main features of the aerosol profile, such as distinctive layers, quite consistently in the five selected case studies. However, several discrepancies can be observed in the extinction coefficient profiles. A good agreement is found in the biomassburning aerosol layer, but not in the dust aerosols layer where the FAAM measurements are significantly higher. This overestimation in dust layers was also noted in Johnson et al. (2008b) and is attributed to over correction for anticipated loss of large particles in the nephelometer and PSAP. A comparison with ARM extinction coefficients measured on the ground level shows that the ULA results are closer to surface 

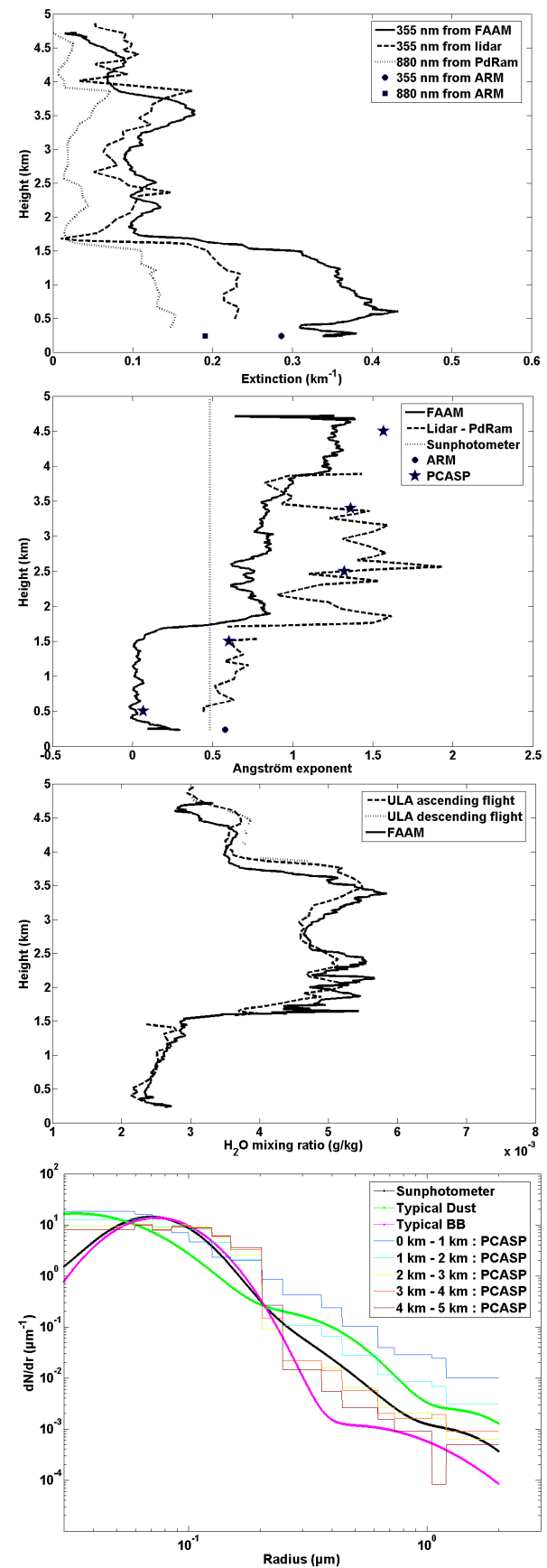

Fig. 1. Vertical profiles of aerosol extinction coefficient at 355 and $880 \mathrm{~nm}$ (a), Angström exponent from FAAM between 450 and $550 \mathrm{~nm}$ (nephelometer and PSAP), ULA between 355 and $880 \mathrm{~nm}$ (LAUVA and PdRam), AERONET between 440 and $870 \mathrm{~nm}$ platforms and PCASP size distribution with mean complex refractive indices (retrieved in this study) between 355 and $800 \mathrm{~nm}$ (b), water vapour mixing ratio from ULA and FAAM (c) observed in the case 1. Values derived from ARM data at the surface are reported by dots. Aerosol size distributions measured from the PCASP, from the sunphotometer (smooth black curve), for typical dust (smooth green curve) and for typical biomass-burning particles (smooth pink curve) for case 1 are also reported (d).
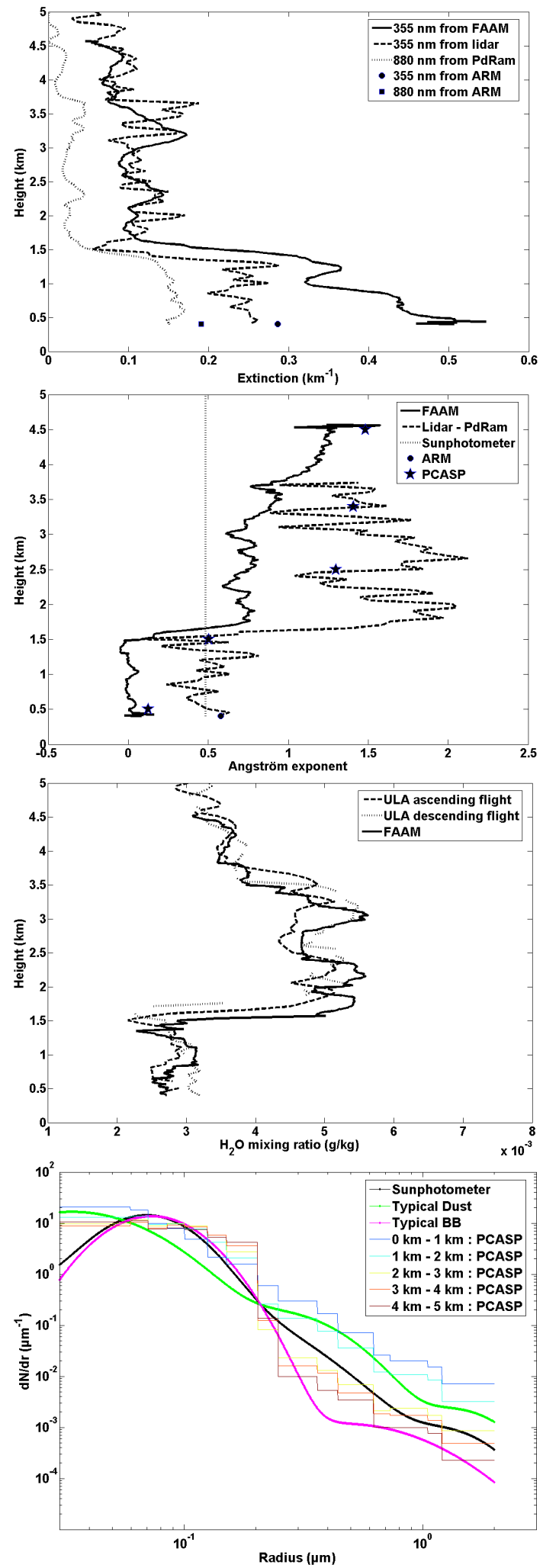

Fig. 2. Same as Fig. 1 for case 2. 

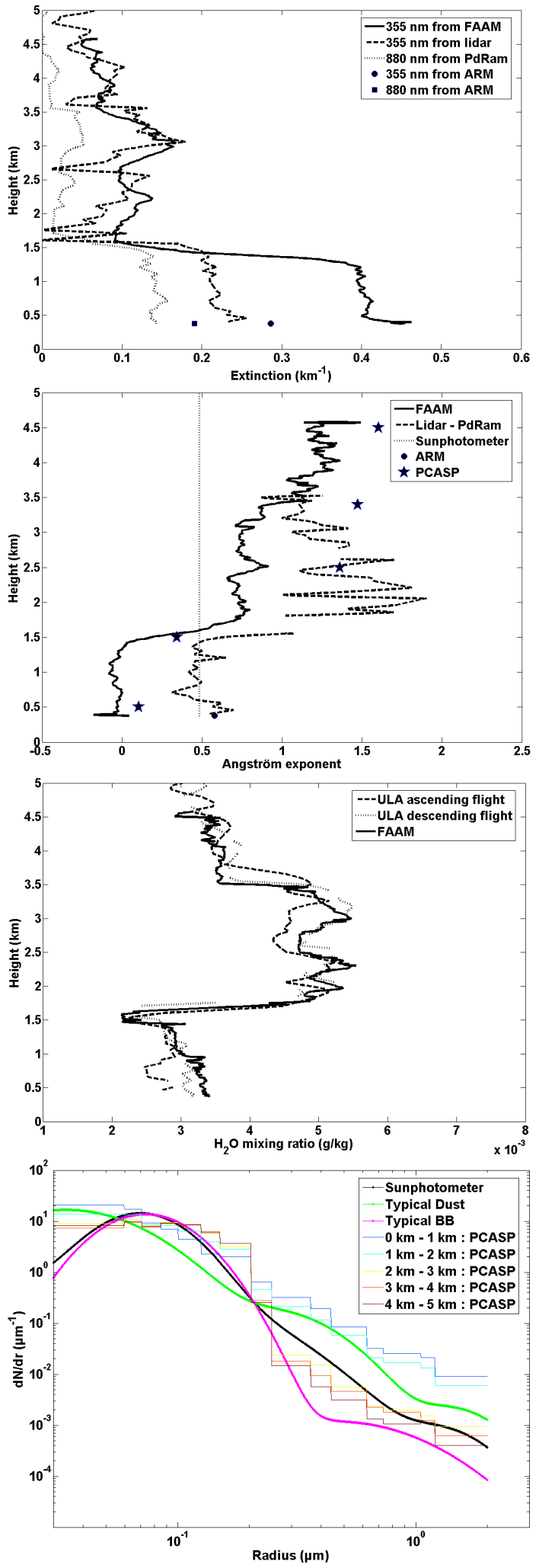

Fig. 3. Same as Fig. 1 for case 3.
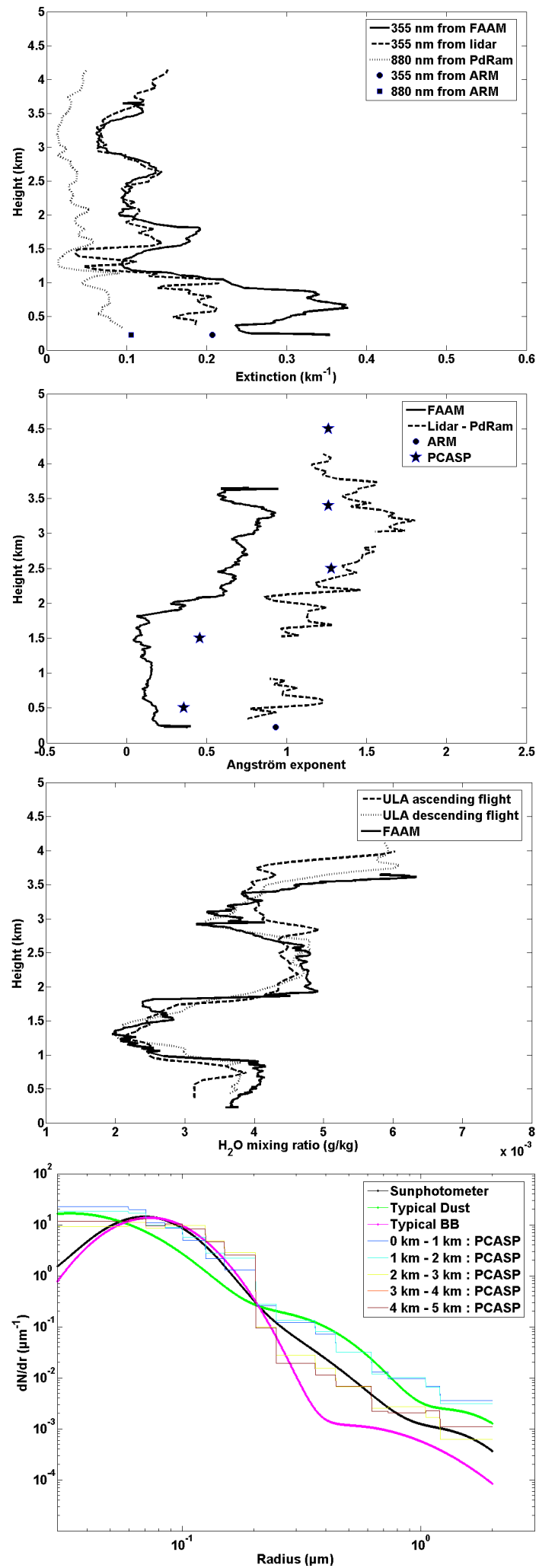

Fig. 4. Same as Fig. 1 for case 4. 

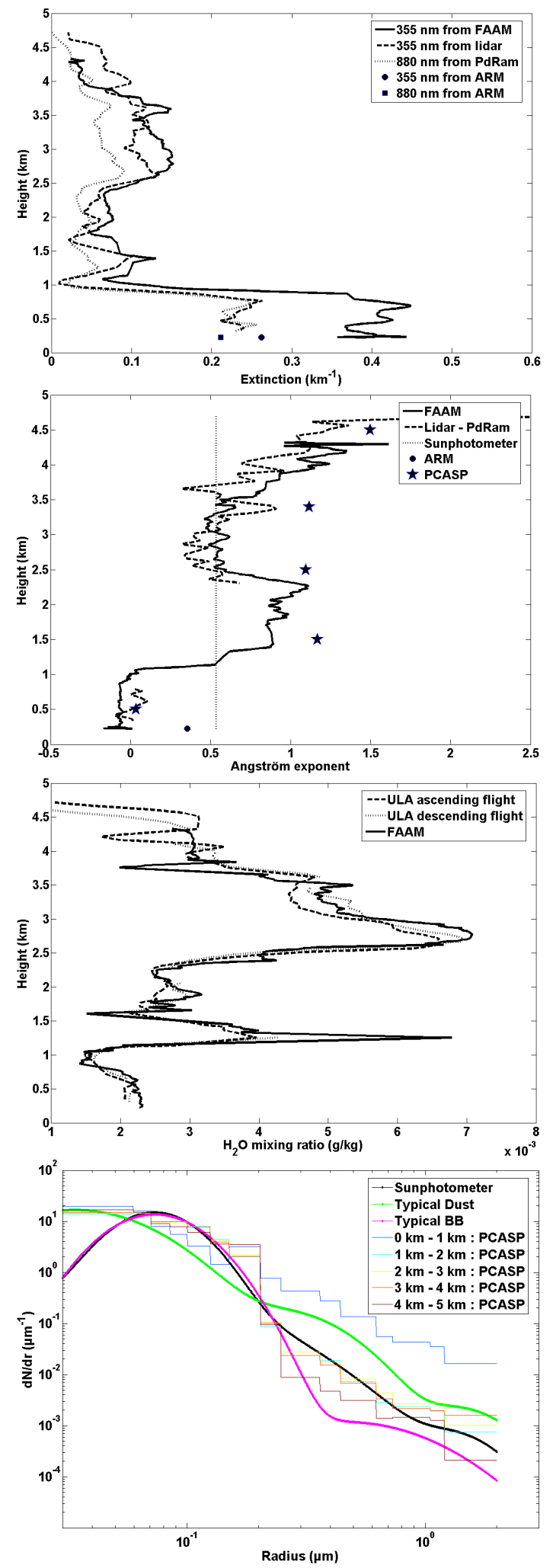

Fig. 5. Same as Fig. 1 for case 5. measurements (within 15\%), a further indications that the aerosol extinction coefficient derived from airborne nephelometer and PSAP data was largely overestimated. This result is in accordance with independent AOD measurements at $355 \mathrm{~nm}$ from Banizoumbou AERONET station (Table 1). The overestimation of FAAM measurements in the dust layer can lead to an optical thickness 33\% higher than AERONET AOD (case 5) (Table 1). On the contrary, an underestimation of AOD by $18 \%$ is observed for ULA data in cases 1 and 3 , whereas a very good agreement was found in cases 2 and 5 (within 7\%). Extinction coefficient retrieved from lidar has an absolute uncertainty of 0.02 , which can explain the differences with AERONET AODs when integrated over the column. These differences may be partly explained by uncertainties associated with aerosol optical properties in both lidar and aircraft in situ measurements, or might be attributed to inhomogeneity of aerosol fields during the sampling. Nevertheless, we should bear in mind that the magnitude of the various biomass-burning aerosol layers are relatively stable and that the differences essentially occur in the sampling of large and aspherical dust particles. Uncertainty in the sampling efficiency of particles larger than about $1.5 \mu \mathrm{m}$ in Rosemont inlets and errors caused in correcting irregular scattering phase functions by standard Andersen and Ogren method (Andersen and Ogren, 1998) can explain such uncertainties. This correction is based on the aerosol size distribution derived from the PCASP, which is limited in the detection of large particles whose contribution, especially over the desert, is clearly significant.

Adding to this uncertainty, there is quite a large disagreement between Angström exponents derived from the FAAM and from ULA, even if the distinction between aerosol layers is clear in both measurements. Generally the graphs of Angström exponent in Figs. 1 to 5 indicate that the sunphotometer-retrieved Angström exponent corresponds both to the column-integrated Angström coefficient as measured by the FAAM and to the value the ULA-derived Angström exponent attains in the mineral dust layer with a larger optical thickness. Nevertheless, this is no longer valid for case 5, where both ULA-derived and FAAM derived Angström exponents are in agreement but differ from the sunphotometer's one. We have to note that the discrepancies can be due to the locations of the flights and to the wind direction. The FAAM aircraft typically covered a horizontal distance of $100 \mathrm{~km}$ during deep profiles, whereas the ULA covered much shorter distances and the flight tracks were directly above Banizoumbou (case 3) or Niamey (cases 1, 2, 4 and 5). Wind measurements obtained on ARM site at the altitude of $6.5 \mathrm{~m}$ above the ground show that the prevailing winds blow from the northwest direction $\left(\sim 330^{\circ}\right)$ on 26 and 28 January (cases 1 to 4 ) and from northeast direction $\left(\sim 50^{\circ}\right)$ on 1 February, which is typical of the Harmattan wind blowing over the Sahel in the dry season. Although the winds generally blew from the North, thus carrying mineral dust particles, a north-westerly wind can also bring a local 
contribution of anthropogenic aerosols because Niamey airport is located South-East from the Niger capital. Pollution with such a local origin superimposes to the dust cloud and can explain Angström exponent values slightly greater than 0 that have been observed on cases 1 to 4 . This turns out to be a local phenomenon in Niamey, which is not representative of situations encountered in Banizoumbou where AERONET station is located.

\subsection{Aerosol size distributions from FAAM PCASP and AERONET}

The differences in aerosol properties between the dust and biomass-burning aerosol layers are partly related to differences in the number size distributions, as observed by the PCASP instrument on the FAAM aircraft (Fig. 1d, Fig. 2d, Fig. 3d, Fig. 4d and Fig. 5d). The size distributions presented in Fig. 1d, Fig. 2d, Fig. 3d, Fig. 4d and Fig. 5d have been normalized and averaged over layers $1000 \mathrm{~m}$ thick, because the data is too noisy without some averaging. Every FAAM profile shows a similar structure in number size distributions and a general decrease in coarse particle concentrations (with radii $<0.3 \mu \mathrm{m}$ ) with altitude. AERONET volume size distribution retrieved from Dubovik inversion algorithm (Dubovik et al., 2000) have been converted in number size distribution and are also shown on Fig. 1d, Fig. 2d, Fig. 3d, Fig. 4d and Fig. 5d. The AERONET retrieval is representative of the total aerosol column. AERONET measurements performed during 2006 and 2007 in Banizoumbou have also been used to extract typical size distributions for dust (40 cases found), selected by an Angström exponent lower than 0.2 and a single-scattering albedo larger than 0.92 , and for biomass-burning particles (52 cases found) selected by an Angström exponent larger than 0.8 and a single-scattering albedo lower than 0.85 at $355 \mathrm{~nm}$. The corresponding "typical" size distributions have been modelled by log-normal distributions and plotted on Fig. 1d, Fig. 2d, Fig. 3d, Fig. 4d and Fig. 5d. In biomass-burning layer, no coarse mode was observed: aerosols are dominated by small particles, between 0.05 and $0.3 \mu \mathrm{m}$ in radius $(r)$. AERONET typical biomassburning log-normal distribution represents the predominant fine mode, containing $99 \%$ of the total number of particles. It has a modal radius of $\sim 0.08 \mu \mathrm{m}$ with a standard deviation of 1.4. The typical biomass-burning aerosol size distribution exhibits a sharp drop in size distribution between $r \sim 0.15$ and $r \sim 0.3 \mu \mathrm{m}$, whereas the typical dust size distribution has a more continuous distribution with more dominant second and third modes. The typical dust log-normal distribution includes three modes: the first one with a mean radius $r \sim 0.05 \mu \mathrm{m}$ and a standard deviation of 1.8 representing $94 \%$ of the particles, a second located at $r \sim 0.3 \mu \mathrm{m}$ and a third one for coarse particles at $r \sim 1.6 \mu \mathrm{m}$, both having a standard deviation of 1.6.
A good agreement is found between these typical size distributions and aircraft measurements, except for case 5 where a disagreement can be noticed in the smaller number concentrations of both second and coarse mode derived from AERONET retrievals when compared to the aircraft data. For all the case studies, the daily local AERONET size distribution is located between the typical size distributions of dust and biomass-burning aerosols, as one would expect since the atmosphere always contained both dust and biomass burning aerosol layers. These results suggest that it is necessary to clearly distinguish between dust and biomass-burning properties in radiative transfer models to assess the radiative forcing of multi-layered structure of aerosols.

\section{Determination of aerosol optical properties and sur- face albedo}

4.1 Aerosol complex refractive index (ACRI) determination

Measurements from the ULA, FAAM and AERONET have been used to retrieve ACRI using a variety of approaches. Each approach leads to a unique set of values for ACRI.

\subsubsection{Approach 1 (A1)}

The determination of both real and imaginary parts requires two constraints. In approach A1 we have used the aerosol extinction coefficient and the BER at $355 \mathrm{~nm}$ as constraints. The principle of the retrieval method has already been described in Raut and Chazette (2007) and was applied to airborne measurements of vertical aerosol profiles in Paris (Raut and Chazette, 2008). Here, the methodology is quite similar but has been improved enabling both the real and the imaginary parts of ACRI to be derived in the same step. As described in Sect. 3, the first five kilometres of the atmosphere have been divided in five sections to allow the averaging of size distributions. At each height level, two look-up tables are built from a Mie model using the size distribution measured by the PCASP at the given altitude. A set of realistic ACRI values are used; real part are assumed to vary from 1.42 to 1.65 and imaginary parts are assumed to vary from $10^{-4}$ to 0.4 . One of the look-up tables contains values of the extinction coefficient and the other contains values of BER. The solution is a unique ACRI value that provides the same extinction coefficient as that measured by the LAUVA in horizontal shooting mode, and the same BER as the one retrieved by Chazette et al. (2007) as a function of altitude. BER values ranged from $0.025 \pm 0.006 \mathrm{sr}^{-1}$ in the dust layer to $0.008 \pm 0.003 \mathrm{sr}^{-1}$ in the biomass-burning layer. The ACRI result is given by the ACRI value at the intersection of the extinction coefficient and BER curves on Fig. 6. Note that BER is mainly sensitive to the imaginary part of ACRI, whereas the extinction coefficient is more sensitive to the real part of ACRI. 


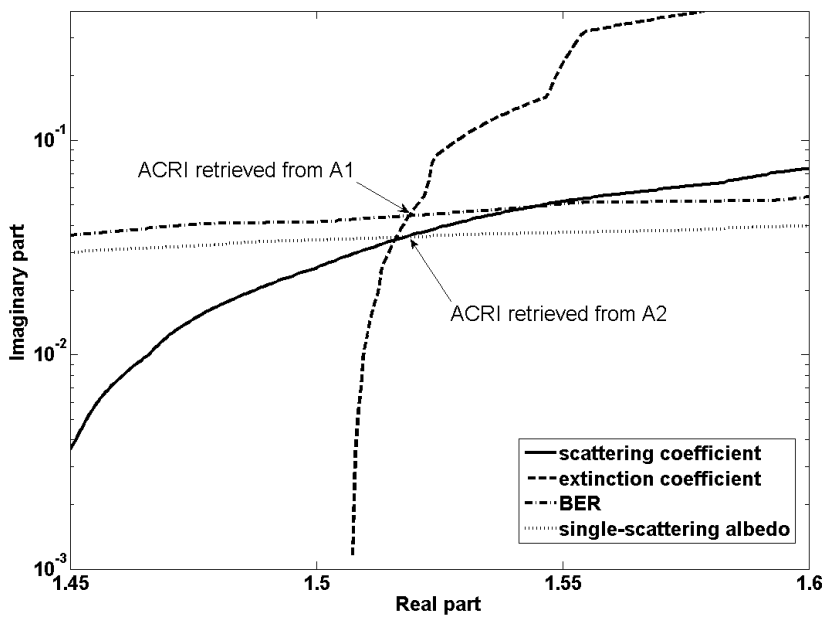

Fig. 6. Illustration of ACRI retrievals from methods A1 and A2: ACRI couples satisfying both measured extinction coefficient and BER in retrieval method $\mathrm{A} 1$, and satisfying both scattering coefficient and single-scattering albedo in retrieval method A2.

\subsubsection{Approach 2 (A2)}

A similar approach has been taken with the FAAM measurements but the scattering coefficient and single scattering albedo are used as constraints for the ACRI retrieval process. Calculations were performed to create a look-up table of scattering coefficients, real part sensitive, and a look-up table of $\omega_{o}$, principally driven by the imaginary part. When convergence was possible, this method provided a unique solution to ACRI imaginary and real parts in a similar manner to the A1 approach. The curve for aerosol scattering coefficient is given by a solid line on Fig. 6 and the curve for $\omega_{o}$ is given by a dotted line on Fig. 6 . Their intersection provides the ACRI determined from FAAM measurements.

\subsubsection{Approach 3 (A3)}

ACRI is routinely retrieved from inversions of AERONET sunphotometer clear sky Almucantar scans of radiance (Dubovik et al., 2002).

\subsubsection{Approaches 4 (A4) and 5 (A5)}

ACRI retrieval is not always possible since the aerosol load is too low (above $4 \mathrm{~km}$ for 28th January and 1st February) or because the size distribution cannot be efficiently determined, mainly in the dust layer. Pinnick et al. (1976) indeed reported that the scattering may be modelled with some success using Mie code for spherical particles of particle size parameter (ratio of the particle circumference to the wavelength) less than about 5. For larger particles Mie theory can be used to model the near forward scattering, but at nonforward angles Mie theory mis-estimates the scattering. The radius measured by the PCASP may therefore be erroneous for large particles, since Mie scattering theory is implicitly used to derive the radius from the intensity of scattered radiation measured by the PCASP and this assumes that all particles are spheres. It is well known that mineral dust particles are predominantly non-spherical (Dubovik et al., 2006), which contributes to the particle miss-sizing.

As already mentioned in Sect. 3.1, scattering coefficients measured by the nephelometer can also be affected by the use of Mie theory in correction factors. Koepke et al. (1988) showed that in desert aerosol the nonspherical particles systematically increase the equivalent spherical side scatter with a maximum around a scattering angle of $120^{\circ}$, while around $160^{\circ}$ the difference between scattering functions of spheres and nonspheres is small. In our study, the large and wellmarked minimum at $\sim 120^{\circ}$ in the scattering phase function of spherical particles is not present in simulations when spheroids particles are used. Hence, the case of spherical particles corresponds to a minimum for extinction and scattering cross-sections. We have to bear in mind that this result is weakly dependent on the average size parameter and does not necessary apply to all possible size distributions. We have also to notice that, in our study, the scattering is overestimated close to $180^{\circ}$ when assumption of spherical particles is done. The resulting scattering coefficient from airborne nephelometer is thus highly overestimated. In contrast, the extinction coefficient derived from lidar signal is slightly underestimated in comparison with the modelled one from size distribution. Chazette et al. (2007) stated that the relative uncertainty of the ULA-derived extinction is about $10 \%$ mainly due to signal noise and deviations in horizontality. The associated uncertainty in BER was $25 \%$.

These reasons explain why algorithms developed for A1 and A2 approaches have never given any result in the dust layer, except for case 4 (Table 2). In the literature, studies taking into account the nonspherical shape of the particles can be found: aerosols might be spheroids, Chebyshev particles, cylinders (Mishchenko, 1991), or spheres containing voids representing particles occupied by cracks and holes (Pinnick, 1976). We tried to model the aerosols as nonspherical shapes rather than spherical particles, but no differences were found between the results from the Mie model with spherical particles and Mishchenko T-matrix code (Mishchenko et al., 1996) using prolate and oblate particles uniformly distributed over all the possible aspect ratios. This finding is contrary to the results of Perrone et al. (2004). However, Mishchenko et al. (1996) suggested that this phenomenon can occur when large numbers of randomly orientated particles in the sampling chamber are averaged, leading to a smaller error than for individual particle counting. It may be also due to the uncertainties in our measurements, especially of size distribution, and the lack of knowledge on dust morphology. Thus, only Mie code is used in the following. It should be noted that this simplification may not lead to significant errors for a climate forcing calculation since integration over the entire hemisphere is performed (Mishchenko et al., 1997). 
Table 2. ACRI values retrieved at $355 \mathrm{~nm}$ in $1 \mathrm{~km}$-thick layers from the ground (ARM data) to a height of $5 \mathrm{~km}$ for both A1 and A2 approaches. ACRI retrievals from AERONET inversion (A3) over the whole column have also been included, as well as a typical value deduced from a pure dust case.

\begin{tabular}{|c|c|c|c|c|c|c|}
\hline & & Case 1 & Case 2 & Case 3 & Case 4 & Case 5 \\
\hline Altitude & Approach & 26th January & 26th January & 26th January & 28th January & 1st February \\
\hline Ground & A5 & - & - & $1.52-0.007 \mathrm{i}$ & $1.58-0.007 \mathrm{i}$ & - \\
\hline $0-1$ & A1 A2 & $-\quad-$ & $-\quad-$ & -- & $1.48-0.008 \mathrm{i}-$ & $-\quad-$ \\
\hline $2-3$ & A1 A2 & $1.53-0.049 \mathrm{i} \quad 1.53-0.025 \mathrm{i}$ & $1.54-0.048 \mathrm{i} \quad 1.51-0.022 \mathrm{i}$ & -- & $1.55-0.051 \mathrm{i} \quad 1.53-0.022 \mathrm{i}$ & $1.60-0.058 \mathrm{i}-$ \\
\hline $3-4$ & A1 A2 & $1.52-0.045 \mathrm{i} \quad 1.51-0.031 \mathrm{i}$ & $1.56-0.049 \mathrm{i}-$ & $1.47-0.038 \mathrm{i} \quad 1.45-0.028 \mathrm{i}$ & $1.53-0.045 \mathrm{i} \quad 1.62-0.022 \mathrm{i}$ & $1.49-0.047 \mathrm{i} \quad 1.53-0.019 \mathrm{i}$ \\
\hline $4-5$ & A1 A2 & $-1.65-0.055 \mathrm{i}$ & $1.58-0.049 \mathrm{i} \quad 1.49-0.049 \mathrm{i}$ & $1.43-0.035 \mathrm{i}-$ & $-\quad-$ & $-\quad-$ \\
\hline Column & A3 & $1.46-0.013 \mathrm{i}$ & $1.46-0.013 \mathrm{i}$ & $1.46-0.013 \mathrm{i}$ & - & $1.41-0.014 \mathrm{i}$ \\
\hline Dust-like & A4 & - & - & $1.48-0.008 \mathrm{i}$ & - & - \\
\hline
\end{tabular}

Because of these difficulties two alternative approaches have been established to determine ACRI values in dust layers. The first alternative is to use a typical dust-like size distribution from AERONET (see Sect. 3.2) along with ULA optical measurements of both BER and aerosol extinction coefficient (Approach 4, A4). The second alternative is to use the local size distribution measured by the PCASP at the lowest altitude level and try to find the consistent ACRI in Mie code with extinction coefficient and $\omega_{o}$ values observed on the surface (ARM site) (Approach 5, A5). This is similar to the A2 approach described in Sect. 4.1.2 except that the retrieval is constrained by ARM measurements of extinction coefficient and $\omega_{o}$ rather than FAAM measurements.

\subsection{Extinction coefficient, single-scattering albedo and} asymmetry parameter

For each of the 206 wavelengths used in this study (equally spaced by $\sim 2.7 \mathrm{~nm}$ from 200 to $750 \mathrm{~nm}$ ), vertical profiles of extinction coefficient, single-scattering albedo and asymmetry parameter have been assessed. In the A1 approach the extinction coefficient profiles have been determined from lidar-derived extinction coefficient profile at $355 \mathrm{~nm}$ and Angström exponent between $355 \mathrm{~nm}$ (LAUVA) and $880 \mathrm{~nm}$ (PdRam). For the A2 approach the same methodology has been applied with the Angström exponent for extinction, which was determined using a combination of PSAP and nephelometer data from FAAM aircraft (Sect. 3.1). Vertical profiles of single-scattering albedo and asymmetry factor have been obtained from Mie theory assuming the spectral independence of ACRI (Sect. 2.2.1). When ACRI retrieval did not converge to a solution, the ACRI at the nearest altitude has been used instead of it. The modelled Angström exponent retrieved from the PCASP size distributions has been added to Figs. 1 to 5 (panels b). Although it cannot serve to discuss the validity of the measured extinction and scattering coefficients (because the ACRI determination also needs those optical properties), it can be useful to show that the ACRI retrieval method does not trigger off significant bias in the Angström exponent. Finally, the A3 approach based on AERONET observations uses typical values for single- scattering albedo, asymmetry parameter and Angström exponent for biomass-burning and dust layers, as described in Sect. 4.1.3. These optical parameters are then interpolated over the whole wavelength spectrum. The vertical profile of the spectral extinction coefficient has been provided by the extinction (at $355 \mathrm{~nm}$ ) from the lidar, but normalized so that it has the same AOD (Sect. 3.1), and Angström exponent as AERONET in the considered layer.

\subsection{Spectral surface albedo}

We used MODIS BRDF model parameters to combine the black-sky (BSA) and white-sky (WSA) albedos as a function of optical depth and hence calculate "actual" (alb $b_{\text {surf }}$ ) or bluesky albedos. This calculation was based on a look-up table containing values of the fraction of diffuse light provided by MODIS website and established with the help of the 6S code (Second Simulation of the Satellite Signal in the Solar Spectrum, Vermote et al., 1997). The fraction of diffuse light $f$ changes with solar zenith angle $\theta$, optical depth AOD, and band wavelength $\lambda$. Spectral blue-sky albedos used in this study for radiative assessments have then been calculated by the equation:

$$
\begin{aligned}
& \operatorname{alb}_{\text {surf }}(\theta, \lambda, \text { AOD })=\text { WSA }(\lambda) \times \mathrm{f}(\theta, \lambda, \text { AOD })+ \\
& \operatorname{BSA}(\theta, \lambda) \times(1-\mathrm{f}(\theta, \lambda, \text { AOD }))
\end{aligned}
$$

\section{Aerosol optical properties and surface albedo results}

\subsection{ACRI results and discussion}

Table 2 summaries ACRI values retrieved in $1 \mathrm{~km}$ thick layers from the ground to a height of $5 \mathrm{~km}$ for both ULA and FAAM datasets. In the following subsections, the standard deviations given are due to the variability of the dataset. Notwithstanding sensitivity analyses based on a Monte Carlo approach have been performed to assess the uncertainty in the calculation of ACRI. In the computation of ACRI, there is not any propagation of errors since both the real part and the imaginary parts are retrieved in a unique step. This is the result of a function minimization of two variables (Sect. 4.1.1). 
In the case of A1 approach, the uncertainty on ACRI is due to the uncertainties on the extinction coefficient, BER and size distribution. In the case of A2 approach, the uncertainty on ACRI is due to the uncertainties on the scattering coefficient, the single-scattering albedo and the size distribution. Hence, the fact that the different approaches do not constrain the optical parameters in the same manner has been implicitly taken into account. It is as if the isopleths of Fig. 6 were surrounded by error bands. The total uncertainty is given by the surface delimited by the intersections of those bands. This could not be represented on Fig. 6 as the uncertainties on the size distribution correspond to a translation of the isopleths. Monte Carlo approaches have given a total uncertainty of $0.03(0.04)$ on the real part and $0.006(0.012)$ on the imaginary part of ACRI in case of A1 (A2) approach. In this particular case, A1 approach more effectively constrains ACRI values but we have to notice that this does not apply to all cases. The errors on ACRI due to the uncertainties of the measurements are lower than ACRI dataset variability, which is consequently significant.

\subsubsection{In biomass-burning layer}

The retrieval model reached convergence in most of the cases for the atmospheric layers above $2 \mathrm{~km}$, i.e. in biomassburning layers. In general, a good agreement is found for the real part of ACRI between A1 and A2. Not surprisingly, this result can be explained by the good correspondence of extinction coefficients determined by the lidar and airborne nephelometer in the biomass-burning layer. From approach A1, the mean real part of ACRI over the whole period has been assessed to $1.53 \pm 0.04$. The variation of real part is slightly larger for the A2 approach and the mean real part is close to $1.54 \pm 0.06$. The main discrepancies are observed for case 3, where the retrieved values of ACRI are lower for the A1 and A2 approaches. This discrepancy may be linked to uncertainty in the total number of particles measured by the PCASP. Two artefacts also occur in the retrieval as a result of limitations in the aircraft data. In case 4 there is no nephelometer data above $3.7 \mathrm{~km}$ (Fig. 4), leading to a possible overestimated real part for A2 approach between 3 and $4 \mathrm{~km}$ where an elevated biomass-burning layer is observed by both LAUVA and PdRam measurements. The second artefact concerns the particles between 4 and $5 \mathrm{~km}$ for case 1. The aerosol concentration was low and the PCASP, nephelometer and lidar are not able to accurately characterise the aerosol. In the literature, real parts of ACRI for biomass burning aerosol range from 1.5 to 1.6 at visible wavelengths, as reported by the AERONET measurements in Remer et al. (1998). For instance, Haywood et al. (2003c) found a value of 1.54 by applying the Maxwell-Garnett mixing rule to measurements of aerosol chemical composition. Yamasoe et al. (1998) reported a value of $1.53 \pm 0.04$ at $438 \mathrm{~nm}$ using Sun/Sky data measured by the AERONET radiometers in Brazil.
The imaginary part of ACRI is generally less well known than the real part of ACRI. Values of imaginary part derived from A1 $(0.047 \pm 0.006)$ are significantly higher than imaginary parts provided by A2 $(0.029 \pm 0.013)$. The large variability in A2-derived imaginary parts is due to large variations in single-scattering albedo values measured from FAAM; these varied from 0.79 to 0.91 . This variability is mainly attributed to variability in the proportion of biomass burning aerosol and dust and variability in the black carbon content of the biomass burning aerosol component (Johnson et al. 2008a). It is also important to bear in mind that some of the variation of single scattering albedo may be due uncertainties in absorption measurements by the PSAP occur during the conversion of light transmission through the filter into absorption coefficient. A1-retrieved imaginary parts are less variable than A2 values since imaginary parts are predominantly governed by BER, which is almost constant in biomass-burning layer over Niamey (Chazette et al., 2007). Values of $0.01-0.04$ were found by several investigators: Li and Mao (1990), Westphel and Toon (1991), Lenoble (1991), Anderson et al. (1996). During the SAFARI campaign, Haywood et al. (2003c) found 0.025 for fresh biomass-burning aerosols and 0.018 in aged biomassburning plumes at $550 \mathrm{~nm}$, in accordance with the value 0.021 reported by Dubovik et al. (2002) in Africa savannah in Zambia. Guyon et al. (2003) calculated lower values (0.013) but aerosols in Amazonian forest were measured during periods were ambient relative humidity was high (up to $80 \%$ ). During INDOEX Léon et al. (2002) retrieved an imaginary part of 0.03 for aerosol mainly originating from agricultural biomass burning. More recently, authors found higher imaginary parts in biomass-burning layers. Using a conservative value for the imaginary part of the index of elementary carbon (Haywood et al., 2003c), Schkolnik et al. (2007) found a reasonable fit between chemically-derived ACRI and optically-derived ACRI with the mean value 1.52i 0.042 in Brazilian biomass-burning plumes. Wandinger et al. (2002) showed an excellent agreement between remote sensing and in-situ measurements in the center of a biomassburning plume, yielding to rather high ACRI, ranging from $1.56-1.66$ in real part and $0.05-0.07$ in imaginary part in the visible domain.

If we assume that the biomass aerosols are an internal mixture between soot, organic matter and water soluble compounds then it is possible to assess the proportion of soot in the aerosol. Volz (1973) gives ACRI of 1.75-i 0.47 and 1.53-i 0.008 for soot and water soluble compounds, respectively. Water soluble and organic compounds have similar ACRI (Chazette and Liousse, 2001). Therefore, using the relation defined in Horvath et al. (1998), the soot proportion in the biomass aerosol can be assessed as $8 \%$. Ackerman and Toon (1981), Faxvog and Roessler (1978) give a higher value for the imaginary part of ACRI of soot, close to 0.66, which would lead to an estimated soot proportion of about $6 \%$. 


\subsubsection{In dust layer}

Below $2 \mathrm{~km}$, the retrieval model converged to a solution for ACRI for only a few cases. For 26th January, the ACRI retrieval algorithm has given a result from the A2 approach, and indicates smaller values for ACRI than in the upper layers, particularly for the imaginary part (0.008). However, the averaging of the size distribution between 1 and $2 \mathrm{~km}$, implicitly introduced a mixing between biomass-burning aerosols and dust, located below $1.5 \mathrm{~km}$. Consequently, they are not typical ACRI values for mineral dust particles. As indicated in Sect. 4.1.4, we tried two alternative methods for retrieving dust ACRI using either a typical dust size distribution from AERONET (A4), or ARM surface measurements (A5). Convergence of the retrieval was obtained for cases 3 and 4 on 26th and 28th January using the ARM dataset (A5) and for case 3 when the AERONET typical dust size distribution was used (A4). It should be noted, however, that retrieving size distribution information for coarse particles is difficult with a maximum wavelength of $1020 \mathrm{~nm}$ and may result in relatively large errors in the AERONET retrieval. The four ACRI values determined in the dust layer (by any of the approaches described above) have been averaged together providing a mean dust ACRI of $1.52( \pm 0.04)-\mathrm{i} 0.008$ $( \pm 0.001)$ that will be used hereafter. A sensitivity study on the PCASP uncertainties was performed using Monte Carlo simulations based on 200 Gaussian random realizations. Uncertainties as large as 30\% in the PCASP measurements lead to uncertainties of 0.003 on the imaginary part and 0.08 on the real part, which is not surprising given that size distribution mainly governs scattering (particularly in forward direction).

The mean value retrieved in our study $(1.52-\mathrm{i} 0.008)$ is very close to the value of $1.53-\mathrm{i} 0.008$ established by Volz (1973) at the same wavelength; the imaginary parts have identical values. Indeed, single-scattering albedo or BER (governing the imaginary part) are less affected by errors linked to the assumption of spherical particles than scattering or extinction coefficients, which are more strongly linked to the real part. Our retrieved real part value (1.52) agrees in general with available dust measurements but the variability in the techniques and in dust composition lead to a dispersion of about 0.05 in the literature (Patterson et al. 1977; Carlson and Benjamin 1980; Sokolik et al. 1993; Sokolik and Toon 1999). By employing the value 1.53 for the real part in remote sensing, Tanré et al. (1999) showed a good consistency of radiative transfer computations with measurements. It is also in accordance with several models, which suggest that the real part of the refractive index of dust is 1.53 for the visible spectral region (Shettle and Fenn 1979; WMO 1983; Koepke et al. 1997). The imaginary part of ACRI is more difficult to determine as Sokolik and Toon (1996) show variations over 3 orders of magnitude for different mineral dust components. Our retrieval (0.008) is consistent with the value given for the visible spectrum by several models (Shet- tle and Fenn, 1979; WCP, 1986). The ACRI of 1.56-i 0.006 reported by Patterson et al. (1977) is broadly similar. We have to note however that studies showed lower imaginary parts, e.g. 0.003 by Levin et al. (1980) or 0.0015 by Haywood et al. (2003b).

\subsubsection{AERONET retrieval of ACRI over the atmospheric column}

ACRI values retrieved from the A3 approach are also listed in Table 2. These values are from AERONET retrievals in Banizoumbou and are integrated over the entire atmospheric column. ACRI values representative of "pure" biomass-burning aerosols or "pure" dust have been extracted, together with their corresponding single-scattering albedo and asymmetry factor. AERONET ACRI retrievals are often lower than other results and close to the complex refractive index of water (Raut and Chazette, 2007); indeed AERONET gave values of $1.39-\mathrm{i} 0.016$ for biomass-burning aerosols and $1.44-\mathrm{i} 0.002$ for mineral dust. The retrieval for typical biomass-burning particles gave a single-scattering albedo of 0.8 and an asymmetry parameter in the range $0.74-0.75$ and the retrieval for typical dust gave a single scattering albedo of 0.95 and an asymmetry parameter ranging from 0.79 to 0.80 at $355 \mathrm{~nm}$.

\subsection{Single-scattering albedo and asymmetry parameter}

\subsubsection{Single scattering albedo $\left(\omega_{o}\right)$}

At a wavelength of $355 \mathrm{~nm}, \omega_{o}$ range from 0.78 to $0.82(0.79$ to 0.87 ) in the biomass-burning layer and from 0.9 to 0.92 (0.94 to 0.96) in the dust plume for A1 (A2) during the whole period. Smaller values obtained in the A1 approach are not surprising since imaginary parts of the ACRI were larger, suggesting there would be higher absorption. The A3 approach gives a value of 0.8 for typical biomass-burning particles, which is the same as for the A1 approach. For typical dust the A3 approach gives $\omega_{0} \sim 0.95$, which is similar to the value retrieved from the A2 aproach. From the 26th January to the 1st February, AERONET-derived $\omega_{o}$ was 0.84 0.85 at $438 \mathrm{~nm}$ and $0.90-0.91$ at $871 \mathrm{~nm}$. All the approaches suggest that the single-scattering albedo of dust increases with wavelength $(0.97-0.98$ at $550 \mathrm{~nm}$ for A2), in contrast to the biomass-burning layers where no net wavelength dependence can be detected (Bergstrom et al., 2003; Dubovik et al., 2002). This result is in accordance with Meloni et al. (2005) that showed values for dust from 0.81 at $415.6 \mathrm{~nm}$ to 0.94 at $868.7 \mathrm{~nm}$, and for biomass-burning aerosols from 0.82 at $415.6 \mathrm{~nm}$ to 0.80 at $868.7 \mathrm{~nm}$.

Values of $\omega_{o} \sim 0.8$ found in this study for the biomassburning layers indicate a rather high influence of absorption of the particles and are consistent with the FAAM aircraft estimates from DABEX reported in Johnson et al. (2008a) showing $\omega_{o} \sim 0.82$ at $550 \mathrm{~nm}$, although we are reporting values at $355 \mathrm{~nm}$. These findings are comparable with many 


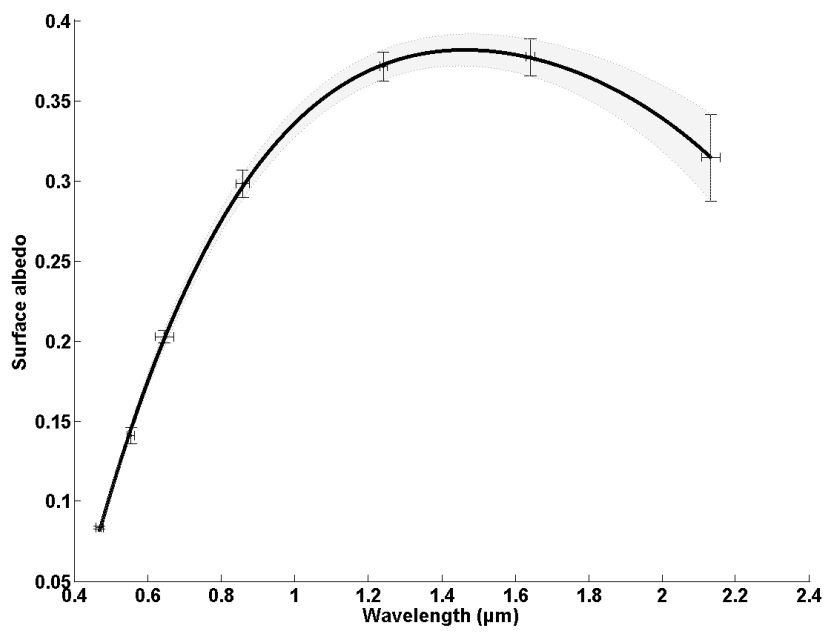

Fig. 7. Surface albedo at 12:00 local time in Niamey as a function of wavelength. The horizontal error bars represent the width of MODIS spectral bands. The vertical error bars are determined from the standard deviation obtained by averaging over the latitudes 13.47 to $13.48^{\circ} \mathrm{N}$ and the longitudes 2.16 to $2.18^{\circ} \mathrm{E}$.

other studies. For example, fresh smoke particles showed $\omega_{o} \sim 0.76$ during SAFARI-2000 (Haywood et al., 2003c), 0.74-0.84 in Brazil (Reid and Hobbs, 1998). Aged biomassburning aerosols have been observed with slightly higher values: 0.83-0.92 during SAFARI (Haywood et al., 2003c), 0.80-0.84 in the case of Brazilian fires (Hobbs et al., 1997; Reid and Hobbs, 1998; Reid et al., 1998). Anderson et al. (1996) reported values of $0.79-0.81$ for dry particles in African and Brazilian outflows over the South Atlantic. Heigher values of $0.85-0.90$ were found for boreal fires (Radke et al., 1988) and for biomass-burning episodes in Southern Africa at $400 \mathrm{~nm}$ (Eck et al., 2003). During INDOEX, Randriamiarisoa et al. (2004) reported values of $\omega_{o}$ between 0.89 and 0.93 at $400 \mathrm{~nm}$.

The mean value retrieved for dust from the A1 approach is small at $355 \mathrm{~nm}(0.91)$ but in agreement with other studies. For example, Moulin et al. (2001) determined the dust absorption and estimated $\omega_{o}$ in the range $0.82-0.90$ in the blue. Kaufman et al. (2001) obtained 0.88 on the coast of Senegal. From the A2 approach $\omega_{o}$ was significantly higher (0.95), which is closer in agreement with value from the SHADE campaign (Haywood et al., 2003b). Tanré et al. (2001) derived $\omega_{o}$ from AERONET measurements at the Banizoumbou site, finding $0.95 \pm 0.03$ at $441 \mathrm{~nm}$. Sokolik and Toon (1996) presented results on the spectral dependence of $\omega_{o}$ for various dust models. They found $\omega_{o}$ around $400 \mathrm{~nm}$ are in the range $0.62-0.95$ and linked these large differences in $\omega_{o}$ values to size distribution and ACRI.

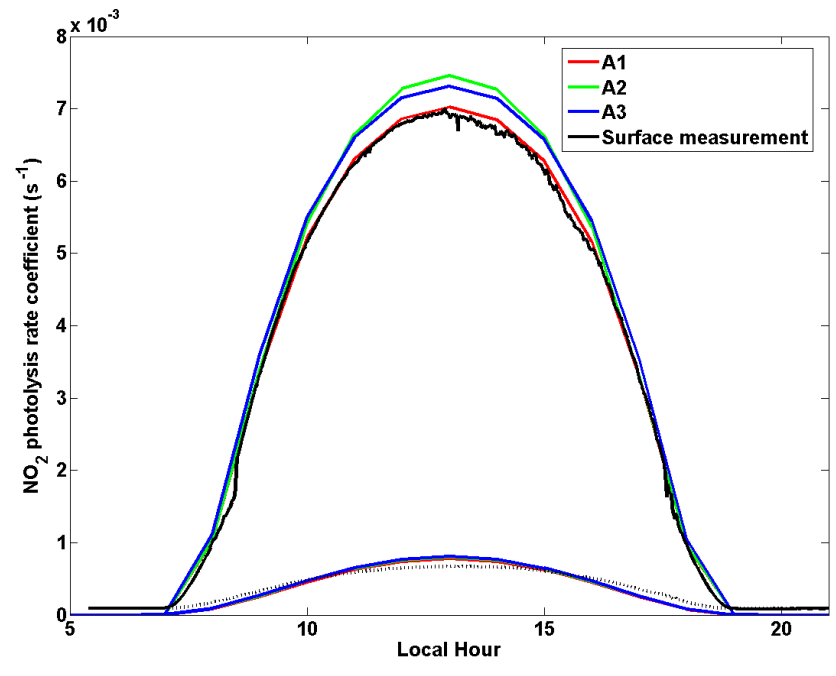

Fig. 8. Downwelling and upwelling $\mathrm{NO}_{2}$ photolysis rate coefficient computed from A1, A2 and A3 approaches using 16-stream discrete ordinates method. Black curves represent the $\mathrm{J}\left(\mathrm{NO}_{2}\right)$ measured by the optical actinometer in Niamey.

\subsubsection{Asymmetry parameter (g)}

In this study, $g$ ranges from 0.71 to 0.73 (0.68 to 0.73 ) in the biomass-burning layer and from 0.73 to 0.75 (0.72 to 0.74 ) in the dust plume following $\mathrm{A} 1$ (A2) at $355 \mathrm{~nm}$. The A3 approach gave values in the range $0.74-0.75$ for typical biomass-burning particles and values ranging from 0.79 to 0.80 for typical dust. Haywood et al. (2003b) reported $g \sim 0.74-0.76$ at $550 \mathrm{~nm}$ and $g \sim 0.64$ at $450 \mathrm{~nm}$ in dust layers indicating a strong spectral dependence of $g$ with $g$ decreasing with increasing wavelength.

\subsection{Surface albedo}

The spectral surface albedo at Niamey is reported on Fig. 7 at 12:00 UTC (Universal Coordinated Time, deviating from local noon from less than one hour), averaged over the latitudes 13.47 and $13.48^{\circ} \mathrm{N}$ and the longitudes 2.16 and $2.18^{\circ} \mathrm{E}$. A sharp increase in spectral surface albedo is observed in the shorter wavelengths, which is in accordance with the visually red-brown surface. We can note relatively small values in the visible spectrum: 0.12 at $550 \mathrm{~nm}$.

\section{UV-Visible aerosol radiative forcing}

\section{$6.1 \mathrm{~J}\left(\mathrm{NO}_{2}\right)$ simulations}

Downwelling and upwelling $\mathrm{NO}_{2}$ photolysis rate coefficient have been simulated for each approach (A1, A2 and A3) using 16-stream discrete ordinates approaches and compared to optical actinometer measurements. Indeed, while the 4-stream discrete ordinates method may be appropriate to 
simulate the irradiances, usually 4 streams are not sufficient for the calculation of photolysis rates, which requires a larger number of streams. Results have been plotted on Fig. 8 for case 5 because the 1st February was the only day presenting clear-sky conditions during the whole day. No significant differences can be observed in the modelled $\mathrm{J}\left(\mathrm{NO}_{2}\right)^{u}$ between the different approaches since values are relatively small. The discrepancies between modelled and observed photodissociation rates have not further been investigated, but can be partly due to the larger uncertainties on upward fluxes than on downward fluxes. The discussion below rather focuses on the downwelling photodissociation rate. The measured $\mathrm{J}\left(\mathrm{NO}_{2}\right)^{d}$ is slightly noisy but the general shape of the curve is easily discernible. All simulations follow the same curve, particularly in the morning (08:00-11:00) and evening (16:00-19:00). For smaller solar zenith angles differences clearly occur between the modelled and measured curves. Modelled $\mathrm{J}\left(\mathrm{NO}_{2}\right)^{d}$ are found higher than the observed one, suggesting that the downward flux has not been sufficiently attenuated through its path in biomass-burning and dust layers in all the simulations. The best simulation of the photolysis rate of $\mathrm{NO}_{2}$ molecule has been obtained using the A1 approach with ULA-derived optical properties since the modelled $\mathrm{J}\left(\mathrm{NO}_{2}\right)$ photolysis rates superimpose on the measured one within $1 \%$, whereas the A3 approach gives within 5\% discrepancy and the A2 approach gives within 12\% discrepancy. This may be because the greater scattering coefficient in the dust layer was not compensated for by the low value of ACRI imaginary part found in the biomass-burning layer from the A2 approach. This low absorption in the biomassburning layer does not attenuate the direct downwelling flux enough. Comparing A1 and A3, the main differences come from $\omega_{o}$ and $g$ because, in case of A3, spectral extinction profiles have been determined using ULA-derived extinction coefficient at $355 \mathrm{~nm}$ and Angström exponent for typical dust or biomass-burning particles. This suggests a good determination of both $\omega_{o}$ and $g$, and therefore of ACRI from A1. We have to note that, in this particular case, the differences observed in comparison with the 4-streams method are not clearly significant. This is linked to a compensation effect between the higher number of photons backscattered by dust in the upward direction and their absorption into the biomassburning layer. Hence, for further discussions on irradiances in this paper, the A1 approach and 4-stream discrete ordinates method will be taken as the reference. This enables an assessment of the importance of a reliable synergy in providing input parameters for radiative calculations.

\subsection{Radiative forcing results and discussion}

UV-visible radiative forcing results have been averaged over $24 \mathrm{~h}$ for the five cases studies, the three optical property retrieval approaches and the 4-stream discrete ordinates method. Results have been summarized in Table 3. The corresponding daily evolutions of radiative forcings have been
Table 3. Radiative forcing results averaged over $24 \mathrm{~h}$ for the five case studies, for the three ACRI retrieval approaches and the 4stream discrete ordinates radiative transfer method.

\begin{tabular}{llrrrrr}
\hline & & Case 1 & Case 2 & Case 3 & Case 4 & Case 5 \\
\hline A1 & $\Delta F_{\text {TOA }}$ & -2.2 & -3.0 & -2.6 & 0.2 & 0.4 \\
A1 & $\Delta F_{\text {BOA }}$ & -20.1 & -22.9 & -20.4 & -19.5 & -23.2 \\
A1 & $\Delta F_{\text {ATM }}$ & 17.9 & 19.9 & 17.8 & 19.7 & 23.6 \\
A1 & $R F E$ & 33.1 & 30.2 & 31.8 & 36.5 & 54.9 \\
A2 & $\Delta F_{\text {TOA }}$ & -9.8 & -10.1 & -9.4 & -8.1 & -7.8 \\
A2 & $\Delta F_{\text {BOA }}$ & -25.3 & -25.3 & -23.9 & -17.4 & -19.7 \\
A2 & $\Delta F_{\text {ATM }}$ & 15.5 & 14.9 & 14.5 & 9.3 & 11.9 \\
A2 & $R F E$ & 18.9 & 19.9 & 19.9 & 17.2 & 19.8 \\
A3 & $\Delta F_{\text {TOA }}$ & -2.8 & -3.3 & -3.4 & -1.8 & -1.8 \\
A3 & $\Delta F_{\text {BOA }}$ & -18.7 & -22.6 & -19.3 & -17.0 & -15.5 \\
A3 & $\Delta F_{\text {ATM }}$ & 15.9 & 19.3 & 15.9 & 15.2 & 13.7 \\
A3 & $R F E$ & 24.5 & 29.7 & 24.4 & 28.1 & 29.8 \\
\hline
\end{tabular}

plotted on Fig. 9. The AODs corresponding to these calculations are shown in Table 1 (A1 uses ULA AOD, A2 uses FAAM AOD, A3 uses AERONET AOD).

\subsubsection{Major features}

The daily averages reported on Table 3 are lower than the instantaneous radiative forcings on Fig. 9, since the integration over the whole day also takes into account the nighttime period. The global retrieved uncertainty on the radiative impacts is only of order $3 \mathrm{~W} / \mathrm{m}^{2}$, which is comparable to the day-to-day variability in TOA and BOA radiative impacts. Such a small uncertainty is due to a compensation of uncertainties in both the size distribution and the complex refractive index. As a matter a fact, when size distribution is underestimated (resp. overestimated), the retrieved ACRI, and particularly the real part, is overestimated (resp. underestimated) so as to converge towards the measured constraints of scattering/extinction coefficients, single-scattering albedo and BER. The resulting change in the spectral single scattering albedo and asymmetry parameter is small. Therefore, the errors on PCASP measurements do not clearly affect the spectral retrieved optical properties and as a consequence the radiative effects. Finally, the uncertainty in radiative effects due to uncertainties in the measurements is of the same order of magnitude in the dust layer than in the biomass burning layers.

The following results are given for the reference method. The mean value over the 5 case studies of the solar energy depletion at the surface by both dust and biomass-burning aerosols is $-21.2( \pm 1.7) \mathrm{W} / \mathrm{m}^{2}$. During daytime, when the solar zenith angle is lower than $70^{\circ}$, the radiative impact on the surface reaches $-60 \mathrm{~W} / \mathrm{m}^{2}$ (Fig. 9). The surface energy budget must be balanced, and thus latent and sensible fluxes will reduce to compensate for this decrease in the net radiative flux. This can affect convective processes and cloud 

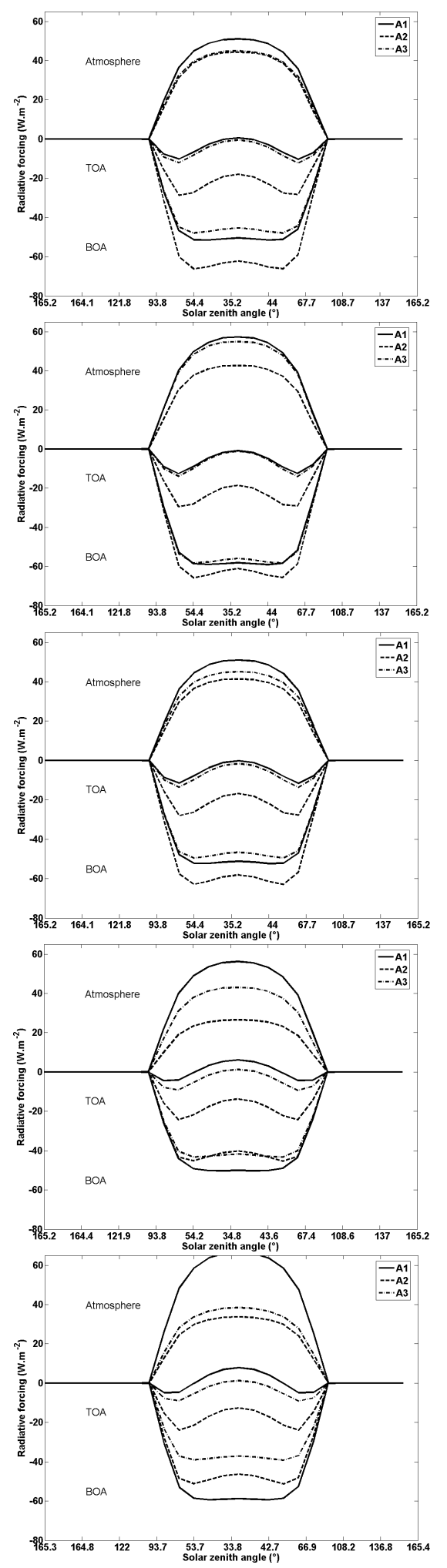

Fig. 9. Daily evolution of radiative forcings at the surface, TOA and in the atmosphere for the three approaches. A1, A2 and A3 using the 4-stream discrete ordinate method.
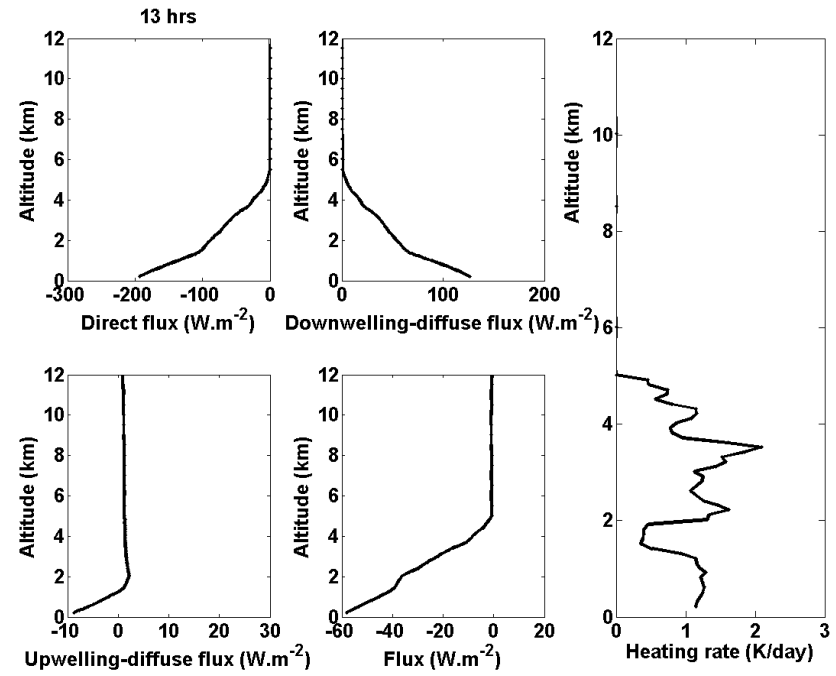

Fig. 10. Vertical profiles of the net radiative fluxes (direct, downwelling-diffuse, upwelling-diffuse and total) obtained on the 26th January (case 2) at 13:00 local time. Aerosol heating rate is also plotted as a function of height with a vertical resolution of $100 \mathrm{~m}$.

formation. At the TOA, the radiative effects are close to zero (mean value of $-1.4 \mathrm{~W} / \mathrm{m}^{2}$ ): $\Delta F_{\mathrm{TOA}}$ is generally negative, indicating a potential cooling of climate, but can become slightly positive with the A1 approach for cases 4 and 5. However these (absolute) values are lower than in previous studies. Johnson et al. (2008b) found a TOA radiative forcing of $-9.8 \mathrm{~W} / \mathrm{m}^{2}$ from FAAM aircraft measurements averaged over the DABEX experiment. The A2 results give very similar results to Johnson et al. (2008b) including the near-infrared wavelengths, which is encouraging since they are based on FAAM data. During the SAFARI2000 campaign in South Africa the normalized $\Delta F_{\mathrm{TOA}}$ by unit optical depth at $500 \mathrm{~nm}$ was estimated to be between -3 and $-5 \mathrm{~W} / \mathrm{m}^{2}$ (Myhre et al., 2003), which is closer to our results from the A1 and A3 approaches (AOD 0.4 at $500 \mathrm{~nm}$ in our study), although higher results should be expected in our study given the presence of dust particles that absorb less efficiently than biomass burning particles. The low radiative forcings at TOA over Niamey can be partly attributed to relatively high absorption properties in the biomass-burning layer (Sect. 5.2.1), preventing a part of the upwelling diffuse flux from returning to space. This is confirmed by the large atmospheric forcing, with a mean value of $19.8 \pm 2.3 \mathrm{~W} / \mathrm{m}^{2}$, indicating the absorption of solar radiations in the atmosphere. $\Delta F_{\text {ATM }}$ can reach $60 \mathrm{~W} / \mathrm{m}^{2}$ during the day (Fig. 9). Accordingly, Pace et al. (2005) found a daily average atmospheric radiative forcing varying between 21.6 and $25.7 \mathrm{~W} / \mathrm{m}^{2}$ for forest fire over the Mediterranean basin in the same wavelength interval $(0.3-0.8 \mu \mathrm{m})$ and a similar columnar amount of aerosols (AOD 0.4 at $416 \mathrm{~nm}$ ). Figure 10 shows that the atmospheric heating rate 
from the aerosol is not homogenous in the vertical column. When the sun is high, the additional heating rate associated with aerosol can reach $2.2 \mathrm{~K} /$ day in the biomass-burning layer, despite the moderate AOD of this layer (about 0.3). This is a consequence of the low single-scattering albedo of the biomass burning aerosol. The maximum value of aerosol heating rate is similar to the $2.05 \mathrm{~K} /$ day reported by Keil and Haywood (2003) for biomass-burning particles (AOD $\sim 0.25$ at $550 \mathrm{~nm}$ ) and $2.2 \mathrm{~K} /$ day by Léon et al. (2002) following INDOEX (AOD $\sim 0.6$ at $532 \mathrm{~nm}$ ). At $20^{\circ}$ solar zenith angle, Pace et al. (2005) showed that the biomassburning layer produced a significant increase in the heating rate by $2.4 \mathrm{~K} /$ day in the first kilometer and $1.5 \mathrm{~K} /$ day over this altitude. Pilewskie et al. (2003) reported two cases of biomass-burning aerosols during the SAFARI-2000 campaign: the instantaneous shortwave heating rates were $4 \mathrm{~K} /$ day in Zambia during intense haze episodes (AOD 1.5 at $500 \mathrm{~nm}$ ) and $1.5 \mathrm{~K} /$ day in Mozambique for less hazy conditions (AOD 0.4 at $500 \mathrm{~nm}$ ). The absorption of shortwave radiation in the dust layer is lower in this study (of order $1 \mathrm{~K} /$ day when the solar zenith angle is close to $30^{\circ}$ ), but we have to bear in mind that our study focuses on UV-visible radiation.

\subsubsection{Daily evolution}

The radiative forcings of aerosols depend of the solar zenith angle, as shown in Fig. 9. The radiative impact of aerosol is larger at 10:00 and 16:00 local hour than at 13:00, i.e. for high solar zenith angles. Everyday the maximum (in absolute value) is obtained at $65^{\circ}$ for $\Delta F_{\mathrm{TOA}}$ and at $55^{\circ}$ for $\Delta F_{\mathrm{BOA}}$. At the TOA, this effect is principally enhanced by the presence of dust particles. The large particles of dust scatter a large part of the incident light in the forward direction. As the solar zenith angle increases, a larger portion of the forward hemisphere includes the region of the upwelling scattered irradiance (Meloni et al., 2005), and hence $\Delta F_{\mathrm{TOA}}$ increases with solar zenith angle up to $65^{\circ}$. At the BOA, the increase of the solar zenith angle enhances the photon path length and thus the attenuation by aerosols, up to a threshold where the atmosphere becomes optically thick. These results are in accordance with many past studies, e.g. Haywood and Shine (1997), Boucher et al. (1998), Myhre and Stordal (2001) and Horvath et al. (2002).

\subsubsection{Comparison between the case studies}

The day-to-day variation in TOA and BOA radiative impacts is small, about $4 \mathrm{~W} / \mathrm{m}^{2}$. In the reference calculation (A1 approach, 4-stream method) $\Delta F_{\mathrm{BOA}}$ ranges from -23.2 to $-19.5 \mathrm{~W} / \mathrm{m}^{2}$ and $\Delta F_{\mathrm{TOA}}$ ranges from -3 to $0.4 \mathrm{~W} / \mathrm{m}^{2}$ (Table 3). The small day-to-day variation occurs because the extinction coefficient profiles were very close from one day to another and the aerosol optical properties barely differed either. $\omega_{o}$ values were $0.88-0.90$ on the 28th January and 1st February and only slightly lower (0.86) on 26th January. A stronger $\omega_{o}$ of biomass-burning particles leads to a larger $F_{\text {diff }}^{d}$ (more scattering) but also to a less attenuated $F_{\text {dir }}^{d}$ (less absorption). Hence, the small day-to-day variations are related to a compensation between these two counterbalancing effects. The lowest values of $\Delta F_{\mathrm{TOA}}$ are also obtained for cases 4 and 5 where a lower AOD reflects less solar radiation back to space. Variations in the atmospheric forcing are small, generally lower than $25 \%$. A more judicious parameter is the daily radiative forcing efficiency (RFE), which is the additional atmospheric radiative forcing per unit optical depth at $355 \mathrm{~nm}$. Values reported in Table 3 show that RFE is nearly constant in the five cases, meaning that the atmospheric radiative forcing is nearly linear in the AOD. It is worth noting that the RFE value retrieved from A1 in case 5 is unexpectedly high due to a large value for ACRI (1.60i 0.058). The ACRI value found between 2 and $3 \mathrm{~km}$ height (Table 2) was applied between 1 and $2 \mathrm{~km}$, because the algorithm was not convergent in this layer. This unusually high value for ACRI associated with a low AOD (0.43, Table 1) considerably enhances the RFE.

\subsubsection{Comparison of the different approaches}

Comparison between A3 and A1. In comparison with the reference calculation (A1, 4-stream method), the use of input parameters derived from AERONET stations (approach A3) does not introduce significant errors in radiative forcing calculations. In our study, we used similar extinction coefficient profiles for A1 and A3 with only small differences due to differences in the Angström exponents used for typical dust and biomass-burning particles. Optical properties derived from A3 were also close to those derived from A1, especially in biomass-burning layers (Sect. 5.2). In the dust layers the single scattering albedos differ slightly between $\mathrm{A} 3$ and $\mathrm{A} 1\left(\omega_{0}\right.$ of 0.95 instead of 0.92) making the A3 dust more diffusive of solar radiation. Therefore, $F_{\text {dir,BOA }}^{d}$ are very similar, but $F_{\text {diff }}^{d}$ are a bit higher for $\mathrm{A} 3$. It partly compensates the attenuation of the direct flux; hence $\Delta F_{\mathrm{BOA}}$ is lower. At the TOA very small differences can be noted in Fig. 9 between A3 and A1. The dust layer slightly scatters more photons back to space in $\mathrm{A} 3$, increasing $\Delta F_{\mathrm{TOA}}$ by a small degree.

Comparison between $\mathrm{A} 2$ and $\mathrm{A} 1$. The differences in radiative forcings between these two approaches are principally due to differences in single scattering albedos and extinction coefficients in the dust layer. In contrast, retrieved values for extinction coefficient, single-scattering albedo and asymmetry factor are very similar in biomass-burning layers. However, in the dust layer, extinction coefficient is higher by a factor of 1.5 to 2 in $\mathrm{A} 2$ than in $\mathrm{A} 1$, and $\omega_{o}$ is also larger (see Sect. 5.2). Below $1.5 \mathrm{~km}$, the importance of the radiative forcing can be mainly attributed to a compensation of two opposite effects: in $\mathrm{A} 2, F_{\mathrm{dir}, \mathrm{BOA}}^{d}$ is indeed more attenuated but $F_{\text {diff,BOA }}^{d}$ is enhanced. In cases 1, 2 and 3, the former effect dominates, resulting in a higher $\Delta F_{\mathrm{BOA}}$. Conversely 

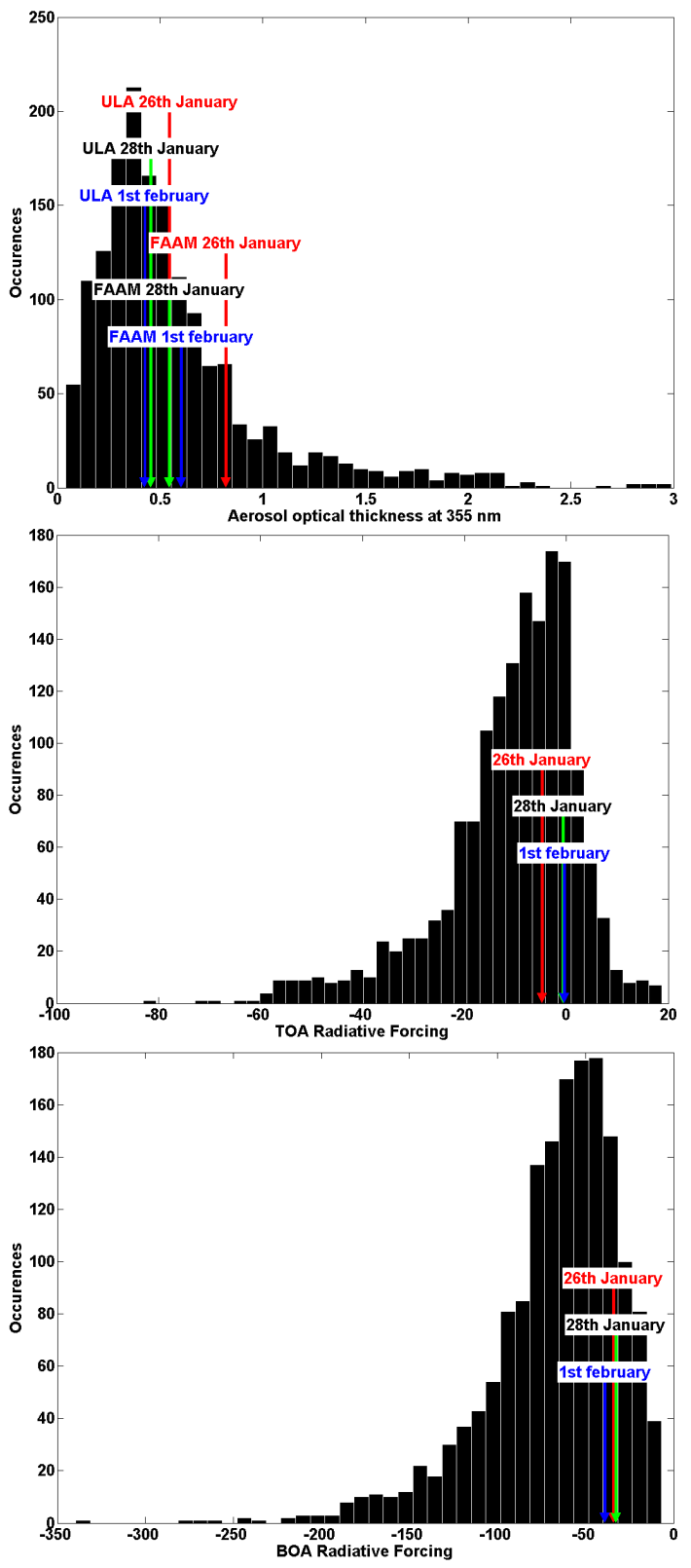

Fig. 11. Histograms of the AOD at $355 \mathrm{~nm}$ (a), TOA radiative forcing (b), and BOA radiative forcing (c) for clear-sky conditions over the years 2006 and 2007 at Banizoumbou, based on AERONET Almucantar inversions. The daily mean values for the case studies on 26th January (red), 28th January (black) and 1st February (blue) are indicated.

in cases 4 and 5, the latter effect is dominant, suggesting a lower $\Delta F_{\mathrm{BOA}}$. This result can be explained by the lower AOD encountered in the dust layer for 28th January and 1st February, leading to a small attenuation of $F_{\text {dir,BOA }}^{d}$, without significantly modifying $F_{\text {diff,BOA }}^{d}$ due to the same scattering properties. At the TOA, the radiative forcing is significantly higher by about $7-8 \mathrm{~W} / \mathrm{m}^{2}$ in daily average (Table 3 ) and up
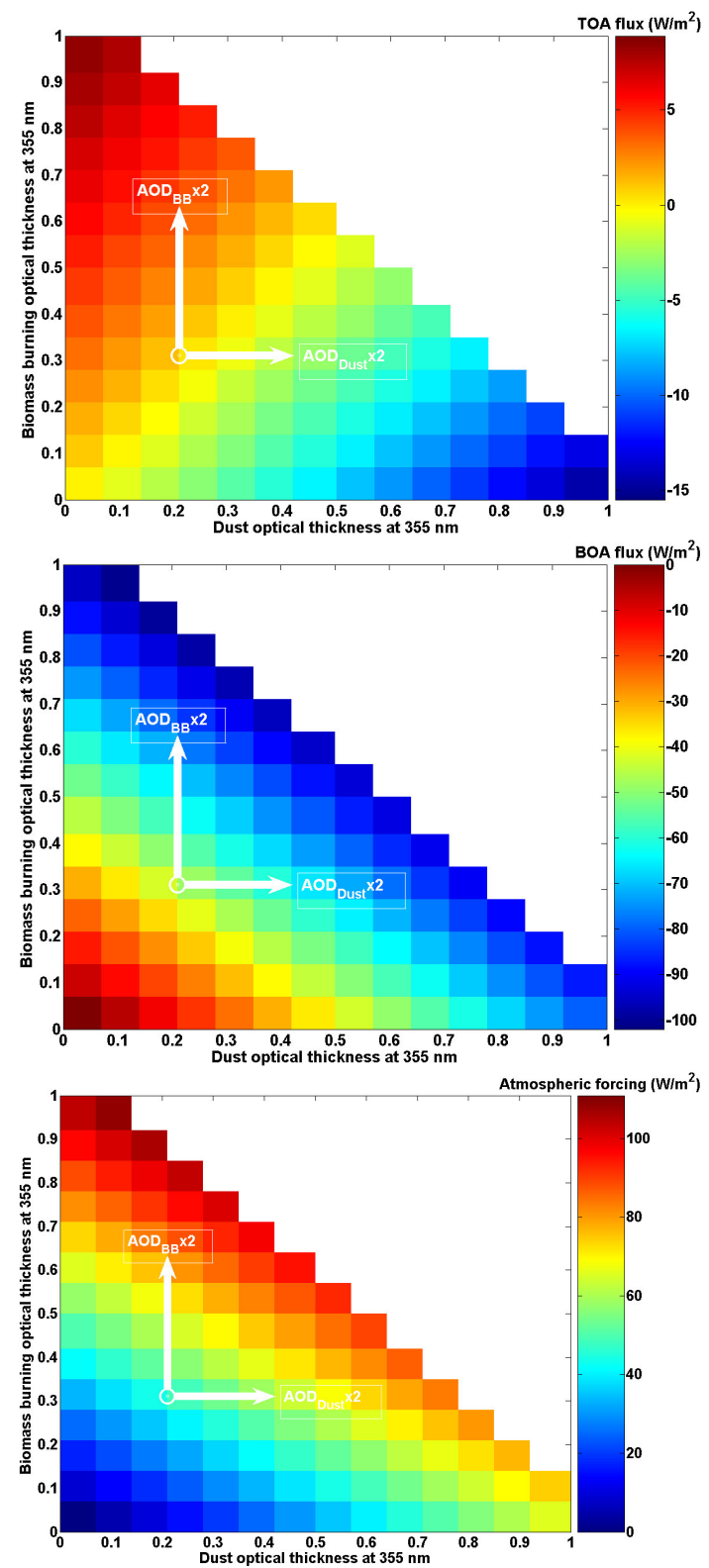

Fig. 12. Radiative forcings at the TOA (a), BOA (b) and in the atmosphere (c) as a function of dust and biomass-burning AOD at 13:00 local time in case 1, when the total AOD does not exceed a value of 1 .

to about $20 \mathrm{~W} / \mathrm{m}^{2}$ during daytime (Fig. 9). This is linked to

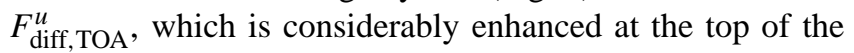
dust layer and almost not attenuated above it through a potential absorption of biomass-burning aerosols. It is worth noting that in the approach A1, $F_{\text {diff }}^{u}$ is very weak, and can be negative (cases 4 and 5), due to a dust layer barely reflecting the incoming radiation ( $\omega_{o}$ of $\left.0.90-0.92\right)$ and to imaginary parts of biomass-burning ACRI twice larger than in A2 approach. 


\subsubsection{Representativeness of radiative calculations}

In a more general context, it is important to assess the representativeness of our results. We used AERONET inversion products obtained over Banizoumbou for clear sky conditions between 2006 and 2007. AERONET directly provides BOA and TOA radiative forcings from broad-band fluxes in the shortwave domain from detailed retrieved aerosol properties. The AERONET AOD data has been interpolated to $355 \mathrm{~nm}$. AODs and TOA and BOA radiative forcings are given in Fig. 11, along with values found in our study. The mean AOD from A1 and A2 approaches and the mean daily TOA and BOA radiative forcings for the 26th January, 28th January and 1st February are located in the centre of the almost Gaussian curve, indicating that our radiative calculations, which are in the range -3 to $0 \mathrm{~W} / \mathrm{m}^{2}$ for $\Delta F_{\mathrm{TOA}}$ and -23 to $-19 \mathrm{~W} / \mathrm{m}^{2}$ for $\Delta F_{\mathrm{BOA}}$ are representative of the region for typical conditions (AOD values are close to 0.5-0.6).

\subsection{Sensitivity analysis}

The sensitivity analysis is only conducted for the reference calculation, which involves approach A1 and the 4-stream discrete ordinates method.

\subsubsection{Influence of optical depth}

The radiative effects described in the previous sections arise from a combination of both dust and biomass-burning aerosols, depleting the net solar radiation at TOA and BOA. The respective impacts of dust and biomass-burning have been discussed but need further investigation. Radiative forcings can differ from the values given in Table 3 when optical properties of the various aerosol layers change or when the vertical distribution of these layers is modified. Fig. 11a shows that the AOD over Niger is usually less than 1. For the period considered in this paper, dust AOD represents about $40 \%$ of the total AOD, the complementary portion being attributed to biomass-burning aerosols. Note that this percentage becomes $70 \%$ in A2 due to the overestimation of scattering in the dust layer (Johnson et al., 2008b). Figure 12 shows the consequences on $\Delta F_{\mathrm{BOA}}, \Delta F_{\mathrm{TOA}}$ and $\Delta F_{\mathrm{ATM}}$ (at 13:00 local hour in case 1) of varying the AOD of the dust and biomass-burning layers whilst keeping the sum of their optical depths lower than 1 . The radiative forcings corresponding to the reference measurements of case 1 are illustrated with a white circle. At the TOA, the radiative forcing seems to be influenced only by the relative proportions of dust and biomass-burning aerosols, suggesting a compensation of backscattering and absorption effects. At the BOA and in the atmospheric column, the radiative forcings are influenced more strongly by the total AOD, as indicated by the coloured bands with a slope close to -1 on Fig. 12 .
When dust AOD is doubled, $\Delta F_{\mathrm{TOA}}$ decreases by $3 \mathrm{~W} / \mathrm{m}^{2}$, $\Delta F_{\mathrm{BOA}}$ decreases by $18 \mathrm{~W} / \mathrm{m}^{2}$ and therefore $\Delta F_{\mathrm{ATM}}$ increases by $15 \mathrm{~W} / \mathrm{m}^{2}$. This significant increase in atmospheric absorption is produced partly by absorption in the dust layer since its $\omega_{0}$ is not huge $(0.90-0.92)$ and partly by enhanced absorption in the biomass-burning layer because of an increase in the number of photons backscattered by mineral dust. In fact, the influence of dust on the heating rate is really visible only in the dust layer itself. In the biomass-burning layer, a doubling of dust AOD triggers off an increase in the heating rate of only $0.1-0.2 \mathrm{~K} /$ day (not shown) due to an additional absorption of the backscattered radiation in the upward direction.

When biomass-burning AOD is doubled, $\Delta F_{\mathrm{TOA}}$ increases by $4 \mathrm{~W} / \mathrm{m}^{2}, \Delta F_{\mathrm{BOA}}$ decreases by $35 \mathrm{~W} / \mathrm{m}^{2}$ and therefore $\Delta F_{\text {ATM }}$ increases by $39 \mathrm{~W} / \mathrm{m}^{2}$. The effects of high imaginary parts of biomass-burning ACRI resulting in absorption are clearly visible: the increase in atmospheric absorption is greater for the biomass burning aerosol than for dust. This suggests that $\Delta F_{\mathrm{TOA}}$ could reach a positive value of $5 \mathrm{~W} / \mathrm{m}^{2}$ during episodes when high plumes of fresh biomass-burning are advected over Niger, which would indicate a potential warming of climate during these episodes.

Radiative calculations have also been performed when either dust or biomass-burning AOD is set to zero. The daily average values for these simulations are reported in $\mathrm{Ta}-$ ble 4 for the five cases. In the absence of biomass-burning aerosols, $\left|\Delta F_{\mathrm{TOA}}\right|$ is enhanced by about 0.6 to $2 \mathrm{~W} / \mathrm{m}^{2}$ depending on the day, since the upwelling-diffuse flux is absorbed less. Without dust, $\Delta F_{\mathrm{TOA}}$ is nearly zero: the effects of backscattering, mainly linked to the surface albedo in this case and of absorption in the biomass-burning layer, cancel. At the surface, the radiative forcing decreases in both cases, but the impact of biomass-burning aerosols on $\Delta F_{\mathrm{BOA}}$ is highly predominant. They can contribute to a $\Delta F_{\mathrm{BOA}}$ of $-18.4 \mathrm{~W} / \mathrm{m}^{2}$ in daily average. The impact of the dust is more variable during the period, varying from -11 to $-8 \mathrm{~W} / \mathrm{m}^{2}$ when the layer height is $1.5 \mathrm{~km}$ (26th January) and from -6 to $-3 \mathrm{~W} / \mathrm{m}^{2}$ when dust are confined in the first kilometre (28th January and 1st February).

\subsubsection{Equivalent surface albedo for dust}

Liao and Seinfeld (1998) indicated that the slope of the linear relation between radiative forcing and AOD (Fig. 12) depends on the surface albedo. They stated that RFE decreased with increasing surface albedo. This result is consistent with our observations. The surface albedo has been modified in our calculations and also the AOD of the dust layer has been varied, which acts in a similar manner to increasing the brightness of the surface when viewed from the point of view of the biomass burning aerosols higher in the atmosphere. This section assesses this equivalent increase in surface albedo generated by the dust layer. 
Table 4. Radiative forcing results simulated when either the AOD of biomass-burning or dust particles has been set to zero, or the vertical positions of the aerosol layers have been inverted but the total AOD has remained constant. Optical properties are taken from the reference approach (A1).

\begin{tabular}{llllllllllllllll}
\hline & & & & & & A1 & A1 without BB layer & A1 without Dust layer & \multicolumn{2}{c}{ A1 inversion } \\
\hline Case 1 & $\Delta F_{\text {TOA }}$ & $\Delta F_{\text {BOA }}$ & $\Delta F_{\text {ATM }}$ & -2.2 & -20.1 & 17.9 & -2.8 & -7.9 & 5.1 & -0.3 & -13.2 & 12.9 & -3.0 & -21.1 & 18.1 \\
Case 2 & $\Delta F_{\text {TOA }}$ & $\Delta F_{\text {BOA }}$ & $\Delta F_{\text {ATM }}$ & -3.0 & -22.9 & 19.9 & -3.6 & -10.7 & 7.1 & -0.5 & -13.6 & 13.1 & -3.8 & -23.7 & 19.9 \\
Case 3 & $\Delta F_{\text {TOA }}$ & $\Delta F_{\text {BOA }}$ & $\Delta F_{\text {ATM }}$ & -2.6 & -20.4 & 17.8 & -3.2 & -10.1 & 6.9 & -0.3 & -11.5 & 11.2 & -3.2 & -21.6 & 18.4 \\
Case 4 & $\Delta F_{\text {TOA }}$ & $\Delta F_{\text {BOA }}$ & $\Delta F_{\text {ATM }}$ & 0.2 & -19.5 & 19.7 & -1.3 & -3.5 & 2.2 & 0.9 & -16.6 & 17.5 & -0.5 & -20.1 & 19.6 \\
Case 5 & $\Delta F_{\text {TOA }}$ & $\Delta F_{\text {BOA }}$ & $\Delta F_{\text {ATM }}$ & 0.4 & -23.2 & 23.6 & -1.6 & -5.8 & 4.2 & 1.3 & -18.4 & 19.7 & -0.3 & -24.0 & 23.7 \\
\hline
\end{tabular}

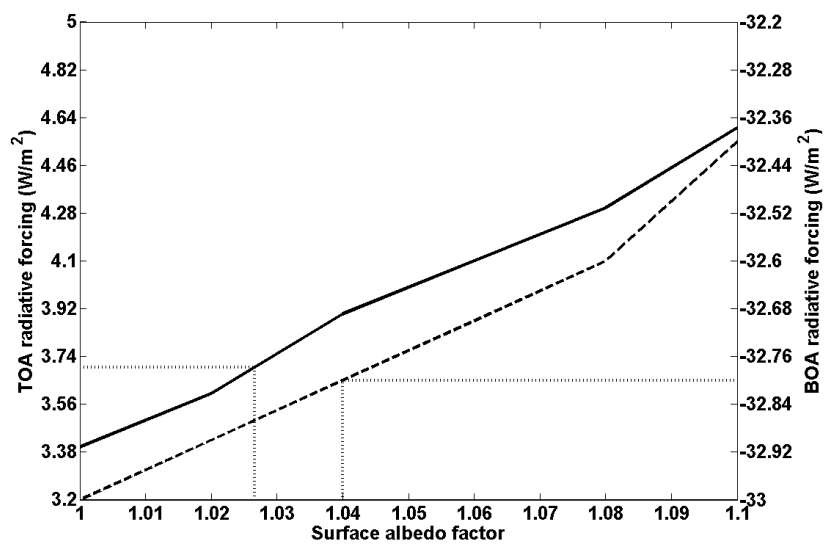

Fig. 13. Variation of the radiative forcings at 13:00 local time for case 1 at TOA (solid line) and BOA (dashed line) with a surface albedo multiplication factor for a layer of biomass-burning aerosols (AOD of dust set to zero). The dotted horizontal lines indicate the radiative forcing due to biomass-burning layers when considering that dust is included as part of the background state, and vertical lines give their corresponding surface albedo factor.

For these simulations, the radiative forcings due only to biomass-burning aerosols (AOD of dust set to zero, Table 4) are calculated for several values of surface albedo and are compared to the forcings due to only biomass-burning aerosols when considering that the dust layer to be part of the background state. Results for case 1 are plotted on Fig. 13 for calculations corresponding to 13:00 local time. Similar results are observed for other case studies / flights. At BOA, the sum $F_{\text {dir }}^{d}+F_{\text {diff }}^{d}$ is $\sim-40 \mathrm{~W} / \mathrm{m}^{2}$ at 13:00 local time. Neglecting scattering terms of second order, surface albedo acts only on $F_{\text {diff }}^{u}$. Hence, the stronger the surface albedo, the more negative $F_{\text {diff }}^{u}$ and the lower $\left|\Delta F_{\mathrm{BOA}}\right|$. This effect is slightly amplified after the biomass-burning layer up to the TOA. Thus, increasing surface albedo leads to an increase in $\Delta F_{\mathrm{TOA}}$ and a decrease in $\Delta F_{\mathrm{BOA}}$ in absolute values. Surface albedo needs to be enhanced by $4 \%$ (respectively $2.7 \%$ ) so as to give the same value for $\Delta F_{\mathrm{BOA}}$ (resp. $\Delta F_{\mathrm{TOA}}$ ) as the reference values of biomass-burning radiative forcings determined when dust are included as part of the background state (Fig. 13). Those values do not really differ from BOA to TOA, indicating that the impact of the dust layer on the radiative forcing of an elevated biomass-burning layer can truly be considered as equivalent to an increase of the surface albedo by $3-4 \%$.

\subsubsection{Inversion of dust and biomass-burning layers}

This section studies how an inversion of the vertical distribution of the aerosol layers would affect the previous results. For each case we reversed the observed vertical distribution by setting the biomass-burning aerosols below the mineral dust layer, without modifying the total AOD or the properties of dust or biomass-burning aerosol layers. The daily average forcings are summarized in the last column of Table 4. In absolute values, radiative effects increase by 0.7 for $\Delta F_{\mathrm{TOA}}$, by 0.9 for $\Delta F_{\mathrm{BOA}}$ and by 0.2 for $\Delta F_{\mathrm{ATM}}$. These results suggest that shortwave radiative forcings are somewhat sensitive to the vertical distribution of dust and biomass-burning aerosols. However, the sensitivity is different for BOA, TOA and atmospheric forcings. The magnitude of the changes are only of order $5 \%$ for $\Delta F_{\mathrm{BOA}}$ and are negligible for $\Delta F_{\mathrm{ATM}}$ (1\%), but of order $30 \%$ for $\Delta F_{\mathrm{TOA}}$.

Other studies have examined the the role of vertical distribution on daily average shortwave radiative forcings at BOA and TOA. For example, Liao and Seinfeld (1998) found that, for cloud-free conditions, the radiative forcings both at the surface and at the TOA are not sensitive to the altitude of the dust layer. Meloni et al. (2005) confirmed that the TOA radiative forcing of particles characterized by low absorption depends weakly on the vertical profile (different profiles produce up to $10 \%$ variation on the daily average forcing), but added that the vertical distribution of absorbing particles strongly affects the radiative forcing at the TOA. This result is also consistent with Torres et al. (1998) who have shown that, in the case of low surface reflectivity and non-absorbing aerosols, the aerosol layer height has a small effect on the backscattered radiance at $380 \mathrm{~nm}$ at the TOA. However, for moderately absorbing particles, an aerosol layer near the surface is more effective than a layer in the mid troposphere in increasing the backscattered radiance. 
In our study, the fact that the TOA radiative forcing is clearly sensitive to the vertical distribution is linked to the presence of absorbing biomass-burning aerosols. The vertical configuration of the aerosol layers permits the backscattering of solar radiation by mineral dust towards the more absorbing particles in the elevated biomass-burning layer above, thus reducing $\Delta F_{\mathrm{TOA}}$. In the reverse configuration, the dust layer acts as an umbrella reducing the downwelling flux of solar radiation in the biomass-burning layer below, thereby reducing the absorption of solar radiation by the biomass burning aerosol.

\subsubsection{Impact of ACRI}

This section investigates the influence of ACRI variation on radiative forcings. The sensitivity analysis is performed for the A1 approach in the case 3 and involves modifying the ACRI in the biomass-burning layer whilst maintaining the same ACRI in the dust layer since their determination was based on the data obtained on ARM site rather than from ULA data (Sect. 1.4).

A wide range of values for the real parts (1.45 to 1.65) and imaginary parts (0.02 to 0.05$)$ of ACRI have been used for the sensitivity analysis, covering the range of possible values of ACRI for biomass-burning particles suggested in Table 2. Figure 14 gives the values of $\Delta F_{\mathrm{TOA}}, \Delta F_{\mathrm{BOA}}$ and $\Delta F_{\mathrm{ATM}}$ at 13:00 local time for the various ACRI values. These results show significant changes in the radiative forcings. The dependency of radiative forcing on the imaginary part is more pronounced than the dependency on real part. For a given real part, radiative forcing varies by $6 \mathrm{~W} / \mathrm{m}^{2}$, both at the TOA and at the surface, when the imaginary part varies from 0.02 to 0.05 . This represents a variation by about $12 \%$ in the surface radiative forcing but the relative sensitivity is substantially higher at the TOA. These results are in agreement with the results of Liao and Seinfeld (1998) who showed that for pure dust the TOA net forcing was more sensitive to the variation in the imaginary part than surface cooling. In our study, the huge sensitivity at the TOA associated with biomassburning particles, can lead to positive or negative forcing. When the real part is higher, scattering effects are enhanced, leading to more solar radiation scattered up to space, and the negative radiative forcing becomes more important. Conversely, a strong imaginary part increases the absorption coefficient, contributing to a positive radiative forcing at the TOA, and an increase in the atmospheric radiative forcing. At the BOA, when the real part is higher, the radiative forcing is weaker, owing to an increased downwelling-diffuse flux. Fig. 14 also shows the retrieved values of ACRI for the A1 approach (in white) and A2 approach (in black) over the whole considered period. It is worth noting that all A1derived ACRI values lead to similar radiative effects. The variability of retrieved values for ACRI appears to be a bit higher in the A2 approach.
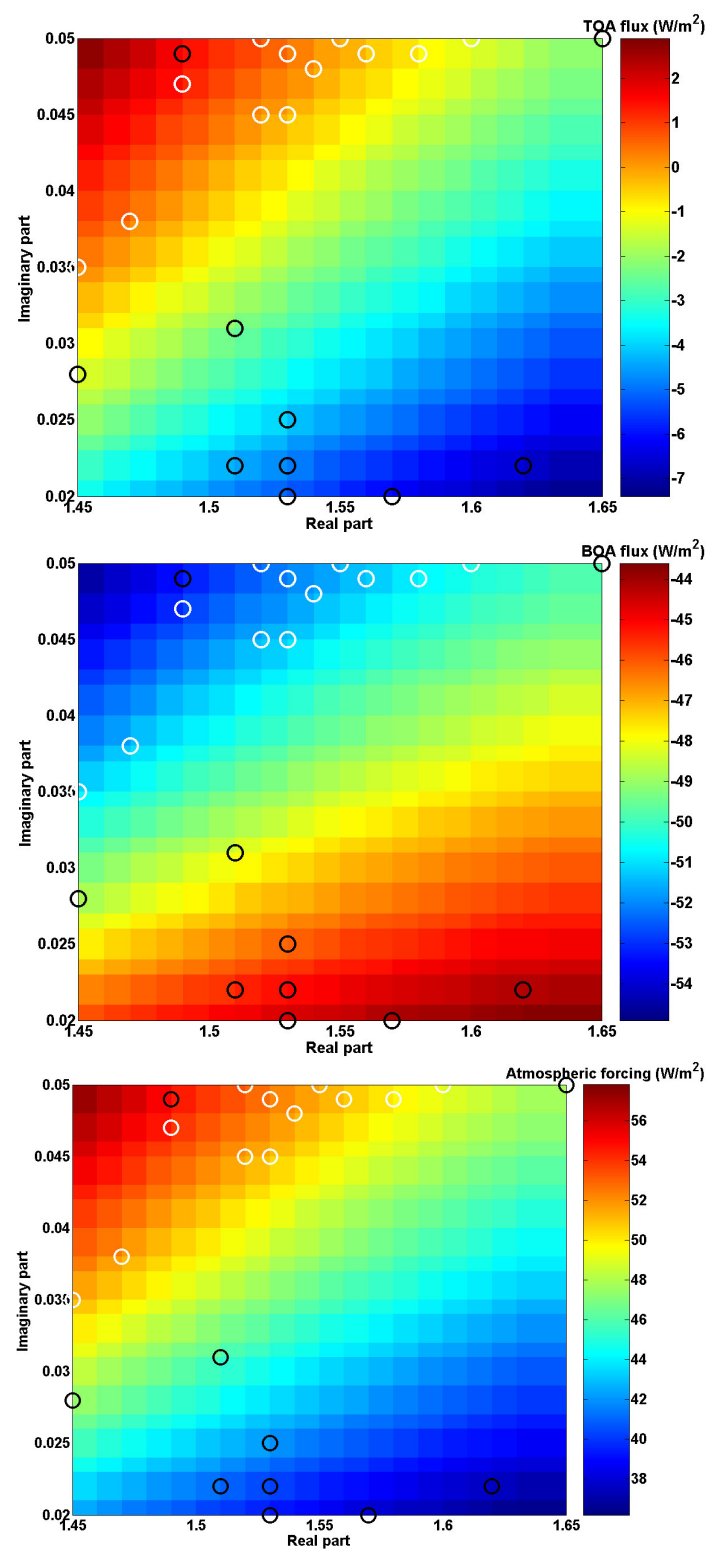

Fig. 14. Radiative forcing values at 13:00 local time for case 3 obtained at TOA (a), BOA (b) and in the atmosphere (c) for the various couples of possible ACRI values for biomass-the burning aerosol. The retrieved values of ACRI are shown as open circles coloured white for A1 and black for A2.

\section{Summary and conclusion}

This study describes observations of aerosol microphysical and optical properties from a variety of platforms, including ground-based, airborne and integrated-column remote sensing measurements in the region surrounding $\mathrm{Ni}$ amey, Niger, in the framework of AMMA-SOP 0. Observations have shown multi-layered structures where mineral dust were located from the surface to an altitude of $1-1.5 \mathrm{~km}$ and biomass-burning particles were found in elevated layers 
from $1.5 \mathrm{~km}$ up to $5 \mathrm{~km}$. Good agreement was found between lidar and airborne measurements of extinction coefficient in the biomass-burning layers. Conversely discrepancies were found in the lower layers of dominated by dust aerosol. We attribute these discrepancies to errors in the measurements of non-spherical particles by nephelometer and particle sizer instruments. Lidar-derived extinction profiles were generally in accordance with aerosol optical thicknesses measured from the sunphotometer. ACRI is a crucial parameter governing both scattering and absorption effects and was determined from a synergy between the lidar and scatterometer on the ULA, the size distribution and optical properties measured onboard the FAAM aircraft, or AERONET retrievals from a case study of a dust layer. The optimal values of ACRI were $1.53( \pm 0.04)-\mathrm{i}, 0.047( \pm 0.006)$ for biomassburning aerosols and $1.52( \pm 0.04)-\mathrm{i} 0.008( \pm 0.001)$ in the dust layer. Corresponding single-scattering albedo values ranged from 0.78 to 0.82 in the biomass-burning layer and from 0.9 to 0.92 in the dust plume. Asymmetry parameters ranged from about 0.71 to 0.73 in biomass-burning layers and from 0.73 to 0.75 in mineral dust layers.

The retrieved optical properties and extinction profiles were used to perform radiative transfer calculations over Niamey in the UV-Visible range, as in e.g. Pace et al. (2005) or Meloni et al. (2005). Simulations of $\mathrm{NO}_{2}$ photolysis rate coefficient increased the confidence in the 4-stream discrete ordinates method associated with ULA dataset. The calculations gave a depletion of solar energy at the surface of $-21.2( \pm 1.7) \mathrm{W} / \mathrm{m}^{2}$ as a daily average. At the TOA, the radiative forcing was slightly negative but very close to zero $\left(-1.4 \mathrm{~W} / \mathrm{m}^{2}\right)$. The corresponding atmospheric radiative forcing was found to be $19.8( \pm 2.3) \mathrm{W} / \mathrm{m}^{2}$. When the solar zenith angle is close to $30^{\circ}$, the additional atmospheric heating rate was of order $1 \mathrm{~K} /$ day but reached as high as $2.2 \mathrm{~K} /$ day in the peak of the biomass-burning layer. A 2-year record of AERONET measurements shows that these results, obtained for the period 26th January-1st February, are representative for this region under typical AOD conditions.

Sensitivity analyses showed that the AOD of each aerosol layer (dust and biomass burning aerosol) had a strong influence on the radiative budget. In particular, setting the AOD of the dust layer to zero enabled us to assess the impact of the dust on the radiative forcing of the biomass burning layer. Mineral dust located below a more absorbing layer acts in a similar manner to an increase of surface reflectivity, by 3$4 \%$ in our case. The radiative forcing is somewhat sensitive to the vertical distribution of aerosols; primarily, the TOA forcing is affected by the altitude of the biomass burning aerosol layer due to the strong absorption of solar radiation by the biomass burning particles. The magnitude of radiative forcing is very sensitive to the ACRI. The ACRI of biomassburning aerosols plays a major role in the radiative forcing at the TOA because it determines the amount of absorption. Accurate determination of ACRI is therefore crucial for deducing optical properties.
In situ measurements and remote sensing observations of microphysical and optical properties, as well as surface albedo are needed for realistic radiative closure. Since dust and biomass-burning aerosols can affect the radiation balance both near the source and far downwind, in regions where optical and chemical properties of the particles may vary, the determination of the optical parameters requires scrutiny, especially as these are required inputs in climate prediction models.

Acknowledgements. Based on a French initiative, AMMA was built by an international scientific group and funded by a large number of agencies, especially from France, UK, US and Africa. It has been the beneficiary of a major financial contribution from the European Community's Sixth Frame-work Research Programme. Detailed information on scientific coordination and funding is available on the AMMA International web site http://www.ammainternational.org. This work was supported by the Centre National d'Etudes Spatiales (CNES). ASECNA personnel from Air Traffic Control and Meteorology at Niamey airport and the team of the AMMA Operation Centre at IRD-Niamey are greatly acknowledged for their logistical help. Ben Johnson from UK Met Office is particularly acknowledged for his fruitful assistance on the organization of the paper and English corrections. We thank Jim Haywood and Simon Osborne for providing with FAAM data. Joseph Sanak and François Dulac (LSCE) are acknowledged for their involvement in AMMA measurements. Anne Jefferson from NOAA/ESRL is acknowledged from proving with ARM data. We also thank especially Jacques Pelon, Cyrille Flamant, and the professional ULA pilot Franck Toussaint. Philippe Goloub, Didier Tanré, and Bernadette Chatenet are also acknowledged for the AERONET sunphotometer data.

Edited by: P. Formenti

\section{References}

Ackerman, S., Toon, O. B., Stevens, D. E., Heymsfeld, A. J., Ramanathan, V., and Welton, E. J.: Reduction of tropical cloudiness, Science, 288, 1042-1047, 2000.

Ackerman, T. P. and Toon, O. B.: Absorption of visible radiation in atmosphere containing mixtures of absorbing and non absorbing particles, Appl. Opt. 20, 3661-3667, 1981.

Alpert, P., Kaufman, Y. J., Shay-El, Y., Tanré, D., Da silva, A., Schubert, S., and Joseph, J. H.: Quantification of dust-forced heating of the lower troposphere, Nature, 395, 367-370, 1998.

Anderson, B. E., Grant, W. B., Gregory, G. L., Browell, E. V., Collins, J. E., Sachse, G. W., Bagwell, D. R., Hudgins, C. H., Blake, D. R., and Blake, N. J.: Aerosols from biomass burning over the tropical South Atlantic region: distributions and impacts, J. Geophys. Res. (D), 101, 24 117-24 137, 1996.

Anderson, T. L. and Ogren, J. A.: Determining aerosol radiative properties using the TSI 3563 integrating nephelometer, Aerosol Sci. Technol., 29, 57-69, 1998.

Andreae, M. O. and Merlet, P.: Emission of trace gases and aerosols from biomass burning, Global Biogeochem. Cy., 15(4), 955-966, 2001 
Andreae, M. O., Rosenfeld, D., Artaxo, P., Costa, A. A., Frank, G. P., Longo, K. M., and Silva-Dias, M. A. F: Smoking Clouds over the Amazon, Science, 303, 5662, 1337-1342, doi:10.1126/science.1092779, 2004.

Bais, A. F., Madronich, S., Crawford, J., et al.: International Photolysis Frequency Measurement and Model Intercomparison (IPMMI): Spectral actinic solar flux measurements and modeling, J. Geophys. Res., 106(D16), 8543, doi:10.1029/2002JD002891, 2003

Bergstrom, R. W., Pilewskie, P., Schmid, B., and Russell, P. B.: Estimates of the spectral aerosol single scattering albedo and aerosol radiative effects during SAFARI 2000, J. Geophys. Res., 108(D13), 8474, doi:10.1029/2002JD002435, 2003

Bodhaine, B. A., Ahlquist, N. C., and Schnell, R. C.: Threewavelength nephelometer suitable for aircraft measurements of background aerosol scattering coefficient, Atmos. Environ., 10, 2268-2276, 1991.

Bond, T. C., Anderson, T. L., and Campbell, D.: Calibration and intercomparison of filter-based measurements of visible light absorption by aerosols, Aerosol Sci. Tech., 30, 582-600, 1999.

Bond, T. C., Streets, D. G., Yarber, K. F., Nelson, S. M., Woo, J.H., and Klimont, Z.: A technology based global inventory of black and organic carbon emissions from combustion, J. Geophys. Res., 109, D14203, doi:10.1029/2003JD003697, 2004.

Boucher, O., Schwartz, S. E., Ackermann, T. P., et al.: Intercomparison of models representing direct shortwave radiative forcing by sulfate aerosols, J. Geophys. Res., 103, 16979-16998, 1998.

Carlson, T. N. and Benjamin, S. G.: Radiative heating rates for Saharan dust. J. Atmos. Sci., 37, 193-213, 1980

Charlson, R. J., Schwartz, S. E., Hales, J. M., Cess, R. D., Coakley, Jr., J. A., Hansen, J. E., and Hoffman, D. J.: Climate forcing by anthropogenic aerosols, Science, 255, 423-430, 1992.

Chazette, P. and Liousse, C.: A case study of optical and chemical ground apportionment for urban aerosols in Thessaloniki, Atmos. Environ., 35(14), 2497-2506, 2001.

Chazette P.: The monsoon aerosol extinction properties at Goa during INDOEX as measured with lidar, J. Geophys. Res., 108, 4187, doi:10.1029/2002JD002074, 2003.

Chazette, P., Sanak., J., and Dulac, F.: New Approach for Aerosol Profiling with a Lidar Onboard an Ultralight Aircraft: Application to the African Monsoon Multidisciplinary Analysis, Environ. Sci. Technol., 41, 8335-8341, 2007.

Dubovik, O., Smirnov, A., Holben, B. N., King, M. D., Kaufman, Y. J., Eck, T. F., and Slutsker, I.: Accuracy assessments of aerosol optical properties retrieved from AERONET sun and sky-radiance measurements, J. Geophys. Res., 105, 9791-9806, 2000.

Dubovik, O., Holben, B. N., Eck, T. F., Smirnov, A., Kaufman, Y. J., King, M. D., Tanre, D., and Slutsker, I.: Variability of absorption and optical properties of key aerosol types observed in worldwide locations, J. Atmos. Sci., 59, 590-608, 2002.

Dubovik, O., Sinyuk, A., Lapyonok, T., et al.: Application of spheroid models to account for aerosol particle nonsphericity in remote sensing of desert dust, J. Geophys. Res., 111, D11208, doi:10.1029/2005JD006619, 2006.

Dulac, F., Chazette, P., Gomes, L., Chatenet, B., Berger, H., and Vinicula dos Santos, J. M.: A method for aerosol profiling in the lower troposphere with coupled scatter and meteorological rawindsondes and first data from the tropical Atlantic off Sahara,
J. Aerosol Sci., 32, 1069-1086, 2001.

Dulac F. and Chazette, P.: Characterization of a multi-layer aerosol structure in the eastern Mediterranean observed with the airborne polarized lidar ALEX during a STAAARTE campaign (June 1997), Atmos. Chem. Phys., 3, 2393-2426, 2003,

http://www.atmos-chem-phys.net/3/2393/2003/.

Eck, T. F., Holben, B. N., Ward, D. E., Mukelabai, M. M., Dubovik, O., Smirnov, A., Schafer, J. S., Hsu, N. C., Piketh, S. J., Queface, A., Le Roux, J., and Slutsker, I.: Variability of biomass burning aerosol optical characteristics in southern Africa during the SAFARI 2000 dry season campaign and a comparison of single scattering albedo estimates from radiometric measurements, J. Geophys. Res., 108(D13), 8477, doi:10.1029/2002JD002321, 2003

Faxvog, F. R. and Roessler, D. M.: Carbon aerosol visibility vs particle size distribution, Appl. Opt. 17, 2612-2616, 1978.

Fouquart, Y., Bonnel, B., Brogniez, G., Buriez, J. C., Smith, L., Morcrette, J. J., and Cerf, A.: Observations of Saharan aerosols: Results of ECLATS field experiment, part II, Broadband radiative characteristics of the aerosols and vertical radiative flux divergence, J. Clim. Appl. Meteor., 26, 38-52, 1987.

Guyon, P., Graham, B., Beck, J., Boucher, O., Gerasopoulos, E., Mayol-Bracero, O. L., Roberts, G. C., Artaxo, P., and Andreae, M. O.: Physical properties and concentration of aerosol particles over the Amazon tropical forest during background and biomass burning conditions, Atmos. Chem. Phys., 3, 951-967, 2003, http://www.atmos-chem-phys.net/3/951/2003/.

Hamonou, E., Chazette, P., Balis, D., Dulac, F., Schneider, X., Galani, E., Ancellet, G., and Papayannis, A.: Characterisation of the vertical structure of Saharan dust export to the Mediterranean basin, J. Geophys. Res., 18, 2257-2270, 1999.

Harshvardhan: Aerosol climate interactions, in: Aerosol-CloudClimate Interactions, edited by: Hobbs, P. V., Academic, San Diego, CA, USA, 75-95, 1993.

Haywood, J. M. and Shine, K. P.: Multi-spectral calculations of the direct radiative forcing of tropospheric sulphate and soot aerosols using a column model, Q. J. R. Meteorol. Soc, 123, 1907-1930, 1997.

Haywood, J., Francis, P., Dubovik, O., Glew, M., and Holben, B.: Comparison of aerosol size distributions, radiative properties, and optical depths determined by aircraft observations and Sun photometers during SAFARI 2000, J. Geophys. Res., 108, 8473, doi:10.1029/2002JD002250, 2003a.

Haywood, J., Francis, P., Osborne, S., Glew, M., Loeb, N., Highwood, E., Tanré, D., Myhre, G., Formenti, P., and Hirst, E.: Radiative properties and direct radiative effect of Saharan dust measured by the C-130 aircraft during SHADE: Solar spectrum, J. Geophys. Res., 108(D18), 8577, doi:10.1029/2002JD002687, 2003 b.

Haywood, J. M., Osborne, S. R., Francis, P. N., Keil, A., Formenti, P., Andreae, M. O., and Kaye, P. H.: The mean physical and optical properties of regional haze dominated by biomass burning aerosol measured from the C-130 aircraft during SAFARI 2000, J. Geophys. Res., 108, doi:10.1029/2002JD002226, 2003c.

Haywood, J., Bharmal, N., Brooks, M. et al.: Overview of the Dust and Biomass burning Experiment and African Multidisciplinary Monsoon Analysis Special Observational Period-0, J. Geophys. Res., doi:10.1029/2008JD010077, in press, 2008.

Hobbs, P. V., Reid, J. S., Kotchenruther, R. A., Ferek, R. J., and 
Weiss, R.: Direct radiative forcing by smoke from biomass burning, Science, 275, 1776-1778, 1997.

Holben, B. N., Eck, T. F., Slutsker, I., et al.: AERONET - A federated instrument network and data archive for aerosol characterisation, Remote Sens. Environ., 66, 1-16, 1998.

Horvath, H.: Influence of atmospheric aerosols upon the global radiation balance, in: Atmospheric particles IUPAC series on analytical and physical chemistry of environmental systems, 5, edited by: Harrison, R. M. and Van Gieken, R., Wiley, NY, USA, 1998.

Horvath, H., Alados Arboledas, L., Olmo, F. J., Jovanovic, O., Gangl, M., Kaller, W., Sanchez, C., Sauerzopf, H., and Seidl, S.: Optical characteristics of the aerosol in Spain and Austria and its effect on radiative forcing, J. Geophys. Res., 107(D19), doi:10.1029/2001JD001472, 2002.

Johnson, D. W., Osborne, S., Wood, R., Suhre, K., Quinn, P. K., Bates, T., Andreae, M. O., Noone, K. J., Glantz, P., Bandy, B., Rudolph, J., and O'Dowd, C.: Observations of the evolution of the aerosol, cloud and boundary-layer characteristics during the 1st ACE-2 Lagrangian experiment, Tellus, 52B, 348-374, 2000.

Johnson, B. T., Osborne, S. R., and Haywood, J. M.: Aircraft measurements of biomass-burning aerosols over West Africa during DABEX, J. Geophys. Res., 113, D00C06, doi:10.1029/2007JD009451, 2008a.

Johnson, B., T., Heese, B., McFarlane, S., Chazette, P., Jones, A. and Bellouin, N.: Vertical distribution and radiative forcing of mineral dust and biomass-burning aerosols over West Africa during DABEX, J. Geophys. Res., 113, D00C12, doi:10.1029/2008JD009848, 2008b.

Joseph, J., Wiscombe, W., and Weiman, J.: The Delta-Eddington Approximation for Radiative Flux Transfer, J. Atmos. Sci., 33, 2452-2459, 1976.

Kaufman, Y. J., Hobbs, P. V., Kirchhoff, V. W. J. H., Artaxo, P., Remer, L. A., Holben, B. N., King, M. D., Ward, D. E., Prins, E. M., Longo, K. M., Mattos, L. F., Nobre, C. A., Spinhirne, J. D., Ji, Q., Thompson, A. M., Gleason, J. F., Christopher, S. A., and Tsay, S.-C.: Smoke, Clouds, and Radiation-Brazil (SCAR-B) experiment, J. Geophys. Res., 103, D24, 31 783-31 808, 1998.

Kaufman, Y. J., Tanré, D., Dubovik, O., Karnieli, A., and Remer, L. A.: Absorption of sunlight by dust as inferred from satellite and groundbased measurements, Geophys. Res. Lett., 28, 14791482,2001

Keil, A. and Haywood, J. M.: Solar radiative forcing by biomass burning aerosol particles during SAFARI 2000: A case study based on measured aerosol and cloud properties, J. Geophys. Res., 108(D13), 8467, doi:10.1029/2002JD002315, 2003.

Koepke, P. and Hess, M.: Scattering functions of tropospheric aerosols: the effects of nonspherical particles, Appl. Opt., 27(12), 1988.

Koepke, P., Hess, M., Schult, I., and Shettle, E. P.: Global aerosol data set, MPI Meteorologie Hamburg Rep. 243, 44 pp., 1997.

Lenoble, J.: The particulate matter from biomass burning: A tutorial and critical review of its radiative impact, in Global Biomass Burning: Atmospheric, Climatic, and Biospheric Implications, edited by: Levine, J. S., MIT Press, Cambridge, MA, USA, 381386, 1991.

Léon, J. F., Chazette, P., Pelon, J., Dulac, F., and Ramdriamarisoa, H.: Aerosol direct radiative impact over the INDOEX area based on passive and active remote sensing, J. Geophys. Res.,
107(D19), 8006, doi:10.1029/2000JD000116, 2002.

Levin, Z., Joseph, J. H., and Mekler, Y.: Properties of Sharav (Khamsin) dust - Comparison of optical and direct sampling data, J. Atmos. Sci., 37, 882-891, 1980.

Li, J., and Mao, J.: Properties of atmospheric aerosols inverted from optical remote sensing, Atmos. Environ., Part A, 24, 2517-2522, 1990.

Liao, H. and Seinfeld, J. H.: Radiative forcing by mineral dust aerosols: sensitivity to key variables. J. Geophys. Res., 103, 31 637-31 645, 1998.

McClatchey, R. A., Fenn, R. W., Selby, J. E. A., Volz, F. E., and Garing, J. S.: Optical properties of the atmosphere, (third edition), Air Force Cambridge Research Laboratories, Report AFCRL72-0497, 1972.

Madronich, S. and Flocke, S.: The role of solar radiation in atmospheric chemistry, in: Handbook Environmantal Chemistry, edited by: Boule, P., Springer-Verlag, Heidelberg, 1-26, 1998.

Mallet, M., Pont, V., Liousse, C., Gomes, L., Pelon, J., Osborne, S., Haywood, J., Dubuisson, P., Roger, J. C., Mariscal, A., Thouret, V. and Goloub P.: Aerosol optical properties over Djougou (Northern Benin) during the AMMA dry season experiment, Estimation of the local direct radiative forcing of biomass burning aerosols, J. Geophys. Res., 113, D00C01, doi:10.1029/2007JD009419, 2008.

Meloni, D. A., Sarra, D., Di Iorio, T, and Fiocco, G.: Influence of the vertical profile of Saharan dust on the visible direct radiative forcing, J. Quant. Spec. Radiat. Trans., 93, 397-413, 2005.

Miller, M. A. and Slingo, A.: The Atmospheric Radiation Measurement (ARM) Mobile Facility (AMF) and its First International Deployment: Measuring Radiative Flux Divergence in West Africa, Bull. Amer. Met. Soc., 88(8), 1229-1244, 2007.

Mishchenko, M. I.: Light scattering by randomly oriented axially symmetric particles, J. Opt. Soc. Am., 8, 871-882, 1991.

Mishchenko, M. I., Travis, L. D., and Macke, A.: Scattering of light by polydisperse, randomly oriented, finite circular cylinders, Appl. Opt., 35, 4927-4940, 1996.

Mishchenko, M. I., Travis, L. W., Kahn, R. A., and West, R. A: Modeling phase functions for dustlike tropospheric aerosols using a shape mixture of randomly oriented polydisperse spheroids, J. Geophys. Res., 102, 16831-16847, 1997

Moulin, C., Gordon, H. R., Banzon, V. F., and Evans, R. H.: Assessment of Saharan dust absorption in the visible from SeaWiFS imagery, J. Geophys. Res., 106(D16), 18 239-18 249, 2001.

Myhre, G. and Stordal, F.: On the tradeoff of the solar and thermal infrared radiative impact of contrails, Geophys. Res. Lett., 28, 3119-3122, 2001.

Myhre, G. F., Berntsen, T. K., Haywood, J. M., Sundet, J. K., Holben, B. N., Johnsrud, M., and Stordal, F.: Modelling the solar radiative impact of aerosols from biomass burning during SAFARI-2000 experiment, J. Geophys. Res., 108(D13), 8501, doi:10.1029/2002JD002313., 2003.

Neckel, H. and Labs, D.: The solar radiation between 3300 and 12500 A, Sol. Phys., 90, 205-258, 1984.

Osborne, S. R., Johnson, B., and Haywood, J.: Physical and optical properties of mineral dust aerosol during the Dust and Biomass Experiment (DABEX), J. Geophys. Res., 113, D00C03, doi:10.1029/2007JD009551, 2008.

Pace, G., Meloni, D., and di Sarra, A.: Forest fire aerosol over the Mediterranean basin during summer 2003 J. Geophys. Res., 110, 
D21202, doi:10.1029/2005JD005986, 2005.

Patterson, E. M., Gillete, D. A., and Stockton, B. H.: Complex index of refraction between 300 and $700 \mathrm{~nm}$ for Saharan aerosol, J. Geophys. Res., 82, 3153-3160, 1977.

Pelon, J., Flamant, C., Chazette, P., Léon, J. F., Tanré, D., Sicard, M. and Satheesh, S. K.: Characterization of aerosol spatial distribution and optical properties over the Indian Ocean from airborne lidar and radiometry during INDOEX'99, J. Geophys. Res., 107(D19), 8029, doi:10.1029/2001JD000402, 2002.

Perrone, M. R., Barnaba, F., De Tomasi, F., Gobbi, G. P. and Tafuro, A. M.: Imaginary refractive-index effects on desert-aerosol extinction versus backscatter relationships at $351 \mathrm{~nm}$ : numerical computations and comparison with Raman lidar measurements, Appl. Opt., 43(29), 2004.

Pilewskie, P., Pommier, J., Bergstrom, R., Gore, W., Rabbette, M., Howard, S., Schmid, B., and Hobbs, P. V.: Solar Spectral Radiative Forcing During the South African Regional Science Initiative, J. Geophys. Res., 108, doi:10.1029/2002JD002411, 2003.

Pinnick, R. G., Carroll, D. E., and Hofmann, D. J.: Polarized light scattered from monodisperse randomly oriented nonspherical aerosol particles: measurements, Appl. Opt., 15(2), 1976.

Prospero, J. M., Ginoux, P., Torres, O., and Nicholson, S.: Environmental characterization of global sources of atmospheric soil dust derived from NIMBUS-7 TOMS absorbing aerosol product, Rev. Geophys., 40(1), doi:10.1029/2000RG000095, 2002.

Radke, L. F, Hegg, D. A., Lyons, J. H., Brock, C. A., Hobbs, P. V., Weiss, R., and Rassmussen, R.: Airborne measurements on smokes from biomass burning, in: Aerosols and Climate, edited by: Hobbs, P. V. and McCormick, M. P., Deepak Publishing, Hampto, VA, USA, 411-422, 1988.

Ramanathan, V., Crutzen, P. J., Lelieveld, J., Althausen, D., Anderson, J., Andreae, M. O., Cantrell, W., Cass, G., Chung, C. E., Clarke, A. D., Collins, W. D., Coakley, J. A., Dulac, F., Heintzenberg, J., Heymsfield, A. J., Holben, B., Hudson, J., Jayaraman, A., Kiehl, T., Krishnamurthi, T. N., Lubin, D., Mitra, A. P., McFarquarh, G., Novakov, T., Ogren, J. A., Podgorny, I. A., Prather, K., Prospero, J. M., Priestley, K., Quinn, P. K., Rajeev, K., Rasch, P., Rupert, S., Sadourny, R., Satheesh, S. K., Sheridan, P., Shaw, G. E., and Valero, F. P. J.: Indian Ocean experiment: An integrated analysis of the climate forcing and effects of the great Indo-Asian haze, J. Geophys. Res., 106(D22), 28 371-28 398, 2001.

Randriamiarisoa, H., Chazette, P., and Mégie, G.: The columnar retrieved single scattering albedo from $\mathrm{NO}_{2}$ photolysis rate, Tellus B, 56, 118-127, 2004.

Raut, J.-C. and Chazette, P.: Retrieval of aerosol complex refractive index from a synergy between lidar, sunphotometer and in situ measurements during LISAIR experiment, Atmos. Chem. Phys., 7, 2797-2815, 2007,

http://www.atmos-chem-phys.net/7/2797/2007/.

Raut, J.-C. and Chazette, P.: Vertical profiles of urban aerosol complex refractive index in the frame of ESQUIF airborne measurements, Atmos. Chem. Phys., 8, 901-919, 2008, http://www.atmos-chem-phys.net/8/901/2008/.

Redelsperger, J.-L., Thorncroft, C., Diedhiou, A., Lebel, T., Parker, D., and Polcher, J.: African Monsoon Multidisciplinary Analysis: An international research project and field campaign, BAMS, 87(12), 1739-1746, doi:10.1175/BAMS-87-12-1739, 2006.

Reid, J. S. and Hobbs, P. V.: Physical and optical properties of smoke from individual biomass fires in Brazil, J. Geophys. Res., 103, 32 013-32 031, 1998.

Reid, J. S., Hobbs, P. V., Ferek, R. J., Blake, D. R., Martins, J. V., Dunlap, M. R., and Liousse, C.: Physical, chemical and optical properties of regional hazes dominated by smoke in Brazil, J. Geophys. Res., 103, 32 059-32 080, 1998.

Remer, L. A., Kaufman, Y. J., Holben, B. N., Thompson, A. M., and McNamara, D.: Biomass burning aerosol size distribution and modeled optical properties, J. Geophys. Res., 103, 31879 $31891,1998$.

Schkolnik, G., Chand, D., Hoffer, A., Andreae, M. O., Erlick, C., Swietlicki, E., Rudich, Y.: Constraining the density and complex refractive index of elemental and organic carbon in biomass burning aerosol using optical and chemical measurements, Atmos. Environ., 41 1107-1118, 2007.

Seinfeld, J. H., Carmichael, G. R., Arimoto, R., et al.: ACE-ASIA: Regional Climatic and Atmospheric Chemical Effects of Asian Dust and Pollution, Bull. Amer. Meteorol. Soc., 85, 367-380, 2004.

Shettle, E. P. and Fenn, R. W.: Models for the Aerosols of the Lower Atmosphere and the Effects of Humidity Variations on their Optical Properties. Project 7670, Air Force Geophysics Laboratory Environmental Research Papers 676, AFGL-TR79-TR79-0214, Massachusetts, USA, 94 pp., 1979.

Sokolik, I. N., Andronova, A., and Johnson, T. C.: Complex refractive index of atmospheric dust aerosols, Atmos. Environ., 27, 2495-2502, 1993.

Sokolik, I. N. and Toon, O. B.: Direct radiative forcing by anthropogenic airborne mineral aerosols, Nature, 381, 681-683, 1996.

Sokolik, I. N. and Toon, O. B.: Incorporation of mineralogical composition into models of the radiative properties of mineral aerosol from UV to IR wavelengths, J. Geophys. Res., 104(D8), 94239444, 1999.

Stamnes, K., Tsay, S. C., Wiscombe, W., and Jayaweera, K.: Numerical stable algorithm for discrete-ordinate-method radiative transfer in scattering and emitting layered media, Appl. Opt., 27, 2502-2509, 1988.

Swap, R. J., Annegarn, H. J., Suttles, J. T., et al.: The Southern African Regional Science Initiative (SAFARI 2000): Dry-Season Field Campaign: An Overview, S. Afr. J. Sci., 98, 125-130, 2002.

Swap, R. J., Annegarn, H. J., Suttles, J. T., King, M. D., Platnick, S., Privette, J. L., and Scholes, R. J.: Africa burning: A thematic analysis of the Southern African Regional Science Initiative (SAFARI 2000), J. Geophys. Res., 108(D13), 8465, doi:10.1029/2003JD003747, 2003.

Tanré, D., Remer, L. A., Kaufman, Y. J., Mattoo, S., Hobbs, P. V., Livingston, J. M., Russell, P. B., and Smirnov, A.: Retrieval of aerosol optical thickness and size distribution over ocean from the MODIS airborne simulator during TARFOX, J. Geophys. Res., 104, 2261-2278, 1999.

Tanré, D., Kaufman, Y. J., Holben, B. N., Chatenet, B., Karnieli, A., Lavenu, F., Blarel, L., Dubovik, O., Remer, L. A., and Smirnov, A: Climatology of dust aerosol size distribution and optical properties derived from remotely sensed data in the solar spectrum, J. Geophys. Res., 106, 18 205-18 217, 2001.

Torres, O., Bhartia, P. K., Herman, J. R., Ahmad, Z., and Gleason, J.: Derivation of aerosol properties from satellite measurements of back scattered ultraviolet radiation: Theoretical basis, J. Geo- 
phys. Res., 103, 17 099-17 110, 1998.

Twomey, S. A., Piepgrass, M., and Wolfe, T. L.: An assessment of the impact of pollution on the global cloud albedo, Tellus, Ser. B, 36, 356-366, 1984.

Volz, F. E.: Infrared Optical Constants of Ammonium Sulfate, Sahara Dust, Volcanic Pumice, and Fly ash, Appl. Opt., 12, 564568, 1973.

Wandinger, U., Muller, D., Bockmann, C., Althausen, D., Matthias, V., Bosenberg, J., Weiss, V., Fieberg, M., Wendisch, M., Stohl, A., and Ansmann, A.: Optical and microphysical characterization of biomass burning and industrial pollution aerosols from multi-wavelength lidar and aircraft measurements, J. Geophys. Res., 107, 8125, doi:10.1029/2000JD000202, 2002.
Westphal, D. L. and Toon, O. B.: Simulations of microphysical, radiative, and dynamical processes in a continental-scale forest fire smoke plume, J. Geophys. Res., 96, 22 379-22 400, 1991.

World Climate Program (WCP): A preliminary cloudless standard atmosphere for radiation computation, World Meteorol. Organ., Geneva, Switzerland, 1986.

WMO: Radiation commission of IAMAP meeting of experts on aerosol and their climatic effects, World Meteorological Organization Rep., WCP55, 28-30, 1983.

Yamasoe, M. A., Kaufman, Y. J., Dubovik, O., Remer, L. A., Holben, B. N., and Artaxo, P.: Retrieval of the real part of the refractive index of smoke particles from Sun/sky measurements during SCAR-B, J. Geophys. Res., 103, 31 893-31 902, 1998. 